\title{
Offshoring, Unemployment, and Wages: The role of labor market institutions
}

\author{
Priya Ranjan ${ }^{1}$ \\ University of California - Irvine \\ pranjan@uci.edu
}

\begin{abstract}
It is shown that when wages are determined through collective bargaining, there is a non-monotonic relationship between the cost of offshoring and unemployment. Starting from a high cost of offshoring, a decrease in the cost of offshoring reduces unemployment first and then increases it. The non-monotonicity of unemployment in the cost of offshoring does not obtain if wages are determined by individual Nash bargaining instead of collective bargaining. The non-monotonic relationship between the cost of offshoring and unemployment is verified through a calibration exercise performed using parameters for Sweden. The calibration exercise predicts that a decrease in the cost of offshoring, starting from the present level, would reduce unemployment in Sweden. In a two country framework of offshoring (source country and host country) it is shown how changes in the labor market institutions in one country affect labor market outcomes in both countries.
\end{abstract}

Key words: offshoring, unemployment, collective bargaining, unions, unemployment benefits, recruitment cost

JEL Classification Codes: F16, J64, J50

\footnotetext{
${ }^{1}$ I would like to thank Joshua Aizenmann, Gabriel Felbermayr, Devashish Mitra, seminar and conference participants at ISI, Delhi, UC-Irvine, UC-Santa Cruz, Claremont McKenna College, and especially two anonymous referees and editor Robert Staiger for extremely helpful and constructive comments.
} 


\section{Introduction}

There has been a resurgence of interest in analyzing the impact of globalization on unemployment. Most papers use models of search unemployment where wages are set through individual Nash bargaining between the worker and the employer, and therefore, do not take into account the role of collective bargaining in the wage setting process. This is a serious omission because for many European countries collective bargaining plays an important role in the wage setting process. When thinking about the importance of collective bargaining in an economy, people usually think about union density which measures the fraction of workforce that is unionized. Union density varied among OECD countries from a low of $8 \%$ in France to a high of $71 \%$ in Sweden in 2007 (OECD, 2010). However, union density grossly understates the percentage of workers covered by collective bargaining. This is particularly so in some countries like France where despite a very low union density, approximately $95 \%$ of workers are covered by collective bargaining (Venn (2009)). In general, in many European countries like Austria, Belgium, Finland, Norway, and Sweden a very high percentage of workers are covered by collective bargaining, much in excess of union density. However, in countries like the U.S., Canada, and Japan only a small percentage of employees are covered by collective bargaining ${ }^{2}$. This motivates us to study the implications of different wage setting institutions for unemployment in a globalized world.

The facet of globalization that we study in this paper is offshoring where by offshoring we mean the sourcing of inputs (goods and services) from foreign countries which enables the fragmentation of production process ${ }^{3}$. One of the main motivations for fragmenting the production process is the ability to procure these inputs at a lower cost from abroad than at home ${ }^{4}$. When production of these inputs moves to foreign countries, the fear at home is that jobs will be lost, unemployment will rise, and

\footnotetext{
${ }^{2}$ Percentage of workers covered by collective bargaining: Austria:99, Belgium:96, Finland:90, Norway:72, Sweden:92, U.S:13, Japan:16, Canada:32. Source: Venn (2009).

${ }^{3}$ Our concept of offshoring includes the procurement of inputs both from a foreign affiliate and a non-affiliate. Sometimes the term foreign outsourcing is used for the latter and the two together are also referred to as "externalization abroad" (see OECD, 2007).

${ }^{4}$ Offshoring is quantitatively important as well. According to OECD (2007), the index of outsourcing abroad of goods and services (value of goods and services offshored as a share of domestic demand) in year 2000 was $81 \%$ in Belgium, $69 \%$ in Netherlands, $61 \%$ in both Denmark and Sweden, and $43 \%$ in Finland. UNCTAD in 2004 found that 39 percent of the top 500 European firms had engaged in offshoring of services (UNCTAD 2004, 153).
} 
wages will fall, making it a salient public policy issue. It is also feared that firms can use the threat of offshoring to force workers to accept lower wages. Therefore, gaining an upper hand in wage bargaining with domestic workers could be an additional motivation for offshoring.

This paper constructs a Pissarides style search model of unemployment to study the impact of offshoring on unemployment and wages. While wages are set through individual Nash bargaining in the standard Pissarides framework, we postulate an institutional setting where wages are set through collective bargaining, and contrast the results with those obtained using individual bargaining. We also extend the model to a two country setting where the price of the offshored input is determined endogenously and analyze the implications of offshoring and changes in the labor market institutions on labor market outcomes in both the source and the host country.

Collective bargaining is modeled using a monopoly union type model where unions set wages in the first stage and then firms choose employment in the second stage. Looking at the small country case first, it is shown that the unemployment of domestic workers could be less in an offshoring equilibrium compared to autarky. The reason is that the mere possibility of offshoring changes the behavior of unions. Seeing the possibility of jobs moving abroad, unions reduce their wage demand in the first stage, which induces firms to hire more domestic workers. More generally, there is a non-monotonic relationship between the cost of offshoring and unemployment. Starting from a cost of offshoring close to the autarky cost of obtaining the input domestically, a decrease in the cost of offshoring decreases unemployment first, and when the cost of offshoring becomes small unemployment starts rising. In all cases, however, whether comparing the autarky equilibrium to the offshoring equilibrium or comparative statics with respect to the cost of offshoring, more offshoring is always associated with lower wages. The result on decreased wages due to a decrease in the cost of offshoring is consistent with the anecdotal evidence that one of the key motivations for offshoring is to reduce the bargaining power of workers/unions.

The result that a mere threat of offshoring can lead to a reduction in wages has important implications for empirical research. The traditional approach is to see if greater offshoring in an industry is associated with lower wages. However, our results suggest that what is important is the offshorability how easy or hard it is to offshore- of an industry rather than the actual amount of offshoring. Ignoring the threat of offshoring as captured in the offshorability of an industry and simply focusing on the actual amount of offshoring, as is done in several empirical studies discussed in the survey by Harrison 
et al.(2011), can lead to an underestimate of the true impact of offshoring on labor market outcomes. Consistent with our view, Blinder (2009) finds that, after controlling for education, most highly offshorable occupations were paying much lower wages in 2004. Similarly, Ebenstein et al. (2009) find that offshoring had a larger impact on the wages of workers engaged in routine tasks- tasks which are easily offshorable.

In addition to providing analytical results, we also undertake a calibration exercise using parameters for a country with pervasive collective agreements, Sweden, and show that the relationship between the cost of offshoring and unemployment is non-monotonic. The calibration exercise predicts that a decrease in the cost of offshoring, starting from the present level, would reduce unemployment in Sweden.

In contrast to the above results, when wages are set through individual Nash bargaining, we do not obtain the non-monotonicity of unemployment in the cost of offshoring. A decrease in the cost of offshoring always leads to an increase in unemployment. Also, unemployment is always higher in an offshoring equilibrium compared to autarky.

Next, we extend the model to a two country case where the price of the offshored input is determined endogenously. To the best of our knowledge, this is the first attempt to study the implications of offshoring for unemployment in a two country framework. We introduce a country Foreign (host country for offshoring) that supplies the offshored input to Home (source country for offshoring). Now, the labor market policies in either country affect the world price of the offshored input and consequently the labor market outcomes in both countries. In this setting it is shown that a decrease in the exogenous element of the offshoring cost reduces Foreign unemployment but the impact on Home unemployment is similar to that in the small open economy case. That is, the non-monotonicity of unemployment with respect to the exogenous element of offshoring cost obtains even when the price of the offshored input is determined endogenously.

Looking at the implications of labor market policies, it is shown that increases in recruitment costs or unemployment benefits in Foreign lead to an increase in the price of the offshored input. Consequently, the impact on Home is similar to that of an increase in the offshoring cost discussed for the small open economy case earlier. That is, Home wages increase but the impact on Home unemployment is ambiguous. As far as the Foreign labor market is concerned, in the case of unemployment benefits Foreign wages increases unambiguously, but the impact on Foreign unemployment is ambiguous. The 
direct effect of increases in unemployment benefits is to increase unemployment in Foreign but the feedback effect working through an induced increase in the price of the offshored input decreases unemployment. Increases in recruitment costs in Foreign have ambiguous effects on Foreign wages and unemployment.

Finally, increases in the recruitment costs or unemployment benefits in Home increase offshoring by Home. The consequent increase in the price of the offshored input increases wages and reduces unemployment in Foreign. Home wages increase but the impact on Home unemployment is theoretically ambiguous.

To sum up, a key prediction of our model is that the impact of offshoring on unemployment in the source country is much more benign in the presence of collective bargaining than in the absence of it. An implication is that offshoring is more likely to increase unemployment in the U.S. where wages are mostly negotiated individually compared to Europe where wages are mostly set by collective bargaining. This is in contrast to some earlier work on globalization and unemployment (e.g. Davis (1998), Moore and Ranjan (2005)) where globalization in the form of trade with unskilled labor intensive countries is likely to lead to a larger increase in unemployment in Europe with an inflexible labor market than in the U.S. which has a more flexible labor market ${ }^{5}$.

\section{$1.1 \quad$ Related Literature}

While the traditional approach of trade economists has been to work with full employment models, in a series of papers Carl Davidson and Steven Matusz studied the implications of introducing unemployment arising from labor market frictions in trade models. The main focus of their work, as discussed in Davidson and Matusz (2004), has been the roles of efficiency in job search, the rate of job destruction and the rate of job turnover in the determination of comparative advantage. Moore and Ranjan (2005) show how trade liberalization in a skill-abundant country can reduce the unemployment of skilled workers and increase the unemployment of unskilled workers. Skill-biased technological change on the other hand, can reduce the unemployment of unskilled workers. Helpman and Itskhoki (2010) use an imperfectly competitive set up with heterogeneous firms to look at how gains from trade and comparative advantage depend on labor market rigidities, and how labor-market policies in a country affect its trad-

\footnotetext{
${ }^{5}$ In Davis (1998) Europe has a binding minimum wage while the U.S. has no minimum wage, while in Moore and Ranjan (2005) Europe has greater unemployment benefit than the U.S.
} 
ing partner. They also study the impact of trade liberalization on unemployment. Trade liberalization in their set up doesn't affect sectoral unemployment, however, the aggregate unemployment is affected due to workers moving from one sector to another. Depending on whether the country's comparative advantage is in the high unemployment or low unemployment sector, trade liberalization could increase or decrease aggregate unemployment ${ }^{6}$. Another related paper, Felbermayr et al. (2011) incorporates search unemployment in a one sector model with firm heterogeneity to study the implications of a bilateral reduction in trade cost on unemployment. Decreases in trade costs in their setting improve the average productivity of firms which in turn reduces the effective cost of posting vacancies leading to higher wages and lower unemployment. The present paper differs from these studies in two respects. One, the facet of globalization studied in these papers is a reduction in the trading cost of final goods while we focus on offshoring. Second, none of these papers allows wages to be determined by collective bargaining $^{7}$.

Mitra and Ranjan (2010) study the impact of offshoring in a two sector model where some jobs in one of the two sectors can be offshored while all the jobs in the other sector must remain onshore ${ }^{8}$. In this setting they show that offshoring could lead to a decrease in unemployment in both sectors if there is sufficient intersectoral mobility of labor. The key to the unemployment reducing effect of offshoring in that paper is the positive productivity effect of offshoring due to a complementarity between the offshored input and the domestically procured input. In contrast, in the present paper, offshored input and domestic labor are perfect substitutes. Therefore, in the absence of collective bargaining offshoring is going to increase unemployment. To isolate the new insight arising from collective bargaining, we have removed the possible productivity effect of offshoring from the model. Bringing in any positive productivity effect of offshoring simply strengthens its unemployment reducing effect.

\footnotetext{
${ }^{6}$ Also see Helpman, Itskhoki and Redding (2010) where trade increases wage inequality but the impact on unemployment is ambiguous.

${ }^{7}$ In the working paper version, Felbermayr et al. (2008) also look at a case where wages and employment are chosen through efficient bargaining between the union and the firm, however, their results for this case are qualitatively similar to those obtained using individual bargaining.

${ }^{8}$ Davidson, Matusz and Shevchenko (2008) also study the implications of offshoring in a job search model. However, their focus is on the offshoring of high-tech jobs on low and high-skilled workers' wages, and on overall welfare.
} 
Using a constant elasticity of substitution production function we verify that our results described above go through when the elasticity of substitution is high. However, for lower elasticity of substitution (complementarity between offshored input and domestic labor) increased offshoring is associated with reduced unemployment irrespective of the wage setting mechanism, that is for both collective bargaining and individual bargaining.

Among the studies on the spillover effects of labor market institutions in a country on its trading partners, Felbermayr et al.(2009) construct a North-North type model with a single composite good where countries export varieties of differentiated intermediate goods to each other. In that setting, decreases in unemployment benefits in one country reduce unemployment everywhere. In our NorthSouth type model in contrast, the impact depends on two things: the wage setting institutions; and whether the changes in labor market policies originate in Home (the source country for offshoring) or Foreign (the host country for offshoring).

Even though Helpman and Itskhoki (2010) is mainly a North-North model focusing on trade between symmetric countries, the paper does analyze the impact of changes in labor market policies in an asymmetric country setting where the asymmetry arises due to differences in unemployment benefits in the two countries. In this setting, increases in unemployment benefits in the differentiated goods sector in a country have a non-monotonic effect on own unemployment but raise unemployment in the trading partner. The mechanism through which these results obtain are completely different from our paper. In the country where unemployment benefits increase, the direct effect is to raise unemployment in the differentiated goods sector which happens to be the high unemployment sector. However, the loss of competitive edge in the differentiated goods sector also means that this sector shrinks and hence workers move out of this sector. The result is that the first effect dominates initially but is outweighed by the second effect for further increases in unemployment benefits. Since the trading partner gets an edge in the differentiated sector, the expansion of the differentiated sector there means an increase in aggregate unemployment. In our framework, the transmission of labor market policies in one country to its trading partner works through changes in the world price of the offshored input.

It is worth mentioning that while the theoretical literature on the relationship between offshoring and unemployment is nascent, there is now a vast literature on other aspects of offshoring. ${ }^{9}$ Following the tradition in standard trade theory, these studies assume full employment.

\footnotetext{
${ }^{9}$ See Helpman (2006) for a review of this literature and Grossman and Rossi-Hansberg (2008) for a recent contribution.
} 
While there is not much theoretical work on the impact of globalization on labor markets characterized by collective bargaining, there is a sizeable empirical literature on the subject, but it mainly focuses on the union wage premium and not on the employment effects of offshoring. Dumont et al. (2006) estimate the impact of globalization on the bargaining power of workers using data from 5 European countries and find that globalization reduces the bargaining power of workers. Using data from Belgium, Brock and Dobbelaere (2006) do not find evidence of trade or inward FDI having an impact on the bargaining power of workers. They find some evidence of technological change having a positive effect on the bargaining power of workers. Finally, using data from Germany, Braun and Scheffer (2007) find that greater international outsourcing reduces the union wage premium of low skilled workers.

The rest of the paper proceeds as follows. In section 2 we provide the basic ingredients of the model. Sections 3 and 4 solve for the autarky and offshoring equilibriums, respectively, for the small open economy case with collective bargaining. Section 5 discusses the small open economy case with individual bargaining. Section 6 provides the calibration exercise. The two country model is developed in section 7 and section 8 concludes.

\section{The Model}

We are first going to describe the autarky equilibrium in a country called "Home". Then we look at the impact of offshoring in Home under the assumption that Home is a small country, that is, it takes the price of the offshored input as given. Then we look at a two country world where a country "Foreign" is the source for offshored inputs. In this case the price of the offshored input is determined endogenously. In the notation below the subscript $h$ under a variable is going to denote its value for Home and the subscript $f$ is going to denote its value for Foreign.

\subsection{The goods market}

There is a single final good $Z$ which can be produced using 3 different technologies. In Home there is a traditional technology that allows one unit of labor to produce $b_{h}$ amount of the final good. In Foreign the traditional technology allows one unit of labor to produce $b_{f}$ amount of the final good. In addition, Home can produce this good using a more sophisticated technology, which requires some 
entrepreneurial input, which is in fixed supply, and hence this technology exhibits diminishing returns to scale. The more sophisticated technology requires producing the final good using an intermediate input which can be produced using either domestic labor or foreign labor. The production function using the sophisticated technology is given by

$$
Z=A X^{\gamma} ; 0<\gamma<1
$$

where $X$ is the amount of the intermediate input used. $\gamma$ captures the diminishing returns and is useful in making the firm size determinate for the purposes of union wage setting. We further assume that one unit of Home labor can produce one unit of the intermediate input. Foreign does not have access to the sophisticated technology, however, it can produce the intermediate input that goes into the production of the final good using sophisticated technology ${ }^{10}$.

\subsection{The labor market}

The labor markets in both countries are characterized by a standard Pissarides (2000) type search friction. To produce the intermediate input $X$, a firm needs to open job vacancies and hire workers. The cost of vacancy is $c_{i}, i=h, f$, in terms of the final good. Denote the total size of work force by $\bar{L}_{i}$, rate of vacancy by $v_{i}$, and the rate of unemployment by $u_{i}$. Define $\theta_{i}=\frac{v_{i}}{u_{i}}$ as the measure of market tightness where $v_{i} \bar{L}_{i}$ is the total number of vacancies and $u_{i} \bar{L}_{i}$ is the number of unemployed workers searching for jobs. Define $m_{i}\left(v_{i}, u_{i}\right)$ as a constant returns to scale matching function given below.

$$
m_{i}\left(v_{i}, u_{i}\right)=\mu_{i} v_{i}^{\delta_{i}} u_{i}^{1-\delta_{i}}
$$

Define $q_{i}\left(\theta_{i}\right)=\frac{m_{i}\left(v_{i}, u_{i}\right)}{v_{i}}$, where $q_{i}\left(\theta_{i}\right) \epsilon t$ is the probability of a vacancy being filled during a small interval of time $\epsilon t$. Since $m_{i}\left(v_{i}, u_{i}\right)$ is constant returns to scale, $q_{i}^{\prime}\left(\theta_{i}\right)=\left(\delta_{i}-1\right) \mu_{i} \theta_{i}^{\delta_{i}-2}<0$. Note that $\frac{m_{i}\left(v_{i}, u_{i}\right)}{u_{i}}=\theta_{i} q_{i}\left(\theta_{i}\right)$ where $\theta_{i} q_{i}\left(\theta_{i}\right) \epsilon t$ is the probability of an unemployed worker finding a job during a small interval of time $\epsilon t$. It follows that $\frac{1}{q_{i}\left(\theta_{i}\right)}$ is the average duration of a vacancy and $\frac{1}{\theta_{i} q_{i}\left(\theta_{i}\right)}$ is the average spell of unemployment. Also, any job can be hit with an idiosyncratic shock with probability $\lambda_{i}$ and be destroyed.

\footnotetext{
${ }^{10}$ This is similar in spirit to the modeling of the South in the Antras and Helpman (2004) model of offshoring where the South cannot produce the varieties of final good but can produce the inputs that go into it.
} 
In steady-state the flow into unemployment must equal the flow out of unemployment:

$$
\lambda_{i}\left(1-u_{i}\right)=\mu_{i} \theta_{i}^{\delta_{i}} u_{i}
$$

The above implies

$$
u_{i}=\frac{\lambda_{i}}{\lambda_{i}+\mu_{i} \theta_{i}^{\delta_{i}}}
$$

The above is the standard Beveridge curve in Pissarides type search models where the rate of unemployment is positively related to the probability of job destruction, $\lambda_{i}$, and negatively related to the degree of market tightness $\theta_{i}$.

Having introduced the common elements of the labor market, we switch to a discussion of autarky equilibrium in Home followed by a discussion of the offshoring equilibrium when Home is a small country. We will return to the two country case later.

\section{Autarky Equilibrium in Home}

To save notation assume that there is a unit mass of identical firms in the economy. Therefore, we do not have to use separate notations for the firm specific variables and the economy specific variables. As well, there is a unit mass of identical unions each with $\bar{L}_{h}$ members and a representative union deals with a representative firm. The interaction between the representative union and the representative firm is modeled using a two stage game where the union proposes a wage in the first stage and the firm chooses employment in the second stage. The timing of moves is same as in the standard monopoly union approach towards wage setting, however, unlike the standard monopoly union model where the union is very large, the representative union in our setting is small in the sense that it takes the economywide market tightness as given while proposing a wage. This framework is analytically tractable and allows us to obtain several analytical results rather than having to rely solely on numerical simulations ${ }^{11}$. As argued by Pissarides (1986), in the context of a search model where firms have to search for workers and any job can be destroyed due to an idiosyncratic shock, letting firms choose

\footnotetext{
${ }^{11}$ Qualitatively similar results obtain using the "right to manage" approach where wages are set in the first stage through bargaining between unions and firms and employment is determined by firms in the second stage. In this setting, wages depend on the bargaining power of unions relative to the bargaining power of firms, and when unions have all the bargaining power in wage setting, the model converges to that of monopoly union. The results using the right to manage approach, based on numerical simulations, were presented in an earlier version of the paper and are available
} 
the level of employment seems to be a more realistic approach. This is also the approach taken by Delacroix (2006) who studies the implications of union wage setting and its interactions with policies in a multisector matching model.

We solve the model backwards where we first solve the representative firm's problem in the second stage for a given wage, and then we solve for the wage in the first stage.

\section{Firm's Problem}

Denote the number of vacancies posted by a firm by $V_{h}$ and the number of workers employed at a firm by $L_{h}$ Assuming that each firm is large enough to employ and hire enough workers to resolve the uncertainty of job inflows and outflows, the dynamics of employment for a firm is

$$
\dot{L_{h}}(t)=\mu_{h} \theta_{h}(t)^{\delta_{h}-1} V_{h}(t)-\lambda_{h} L_{h}(t)
$$

Note that since one unit of Home labor produces one unit of the intermediate good, in autarky $X=L_{h}$, and hence $Z=A X^{\gamma}=A L_{h}^{\gamma}$. Denoting the wage by $w_{h}$ and the rate of discount by $\rho$, the profit maximization problem for the representative firm can be written as

$$
\underset{V_{h}(s), L_{h}(s)}{\operatorname{Max}} \int_{t}^{\infty} e^{-\rho(s-t)}\left\{A\left(L_{h}(s)\right)^{\gamma}-w_{h}(s) L_{h}(s)-c_{h} V_{h}(s)\right\} d s
$$

The firm maximizes (6) subject to (5), taking $w_{h}(s)$ and $\theta_{h}(s)$ as given. Denoting the Lagrangian multiplier associated with (5) by $\psi$ and dropping the time notation $s$ to reduce clutter, the current value Hamiltonian for the firm can be written as

$$
H=A L_{h}^{\gamma}-w_{h} L_{h}-c_{h} V_{h}+\psi\left[\mu_{h} \theta_{h}^{\delta_{h}-1} V_{h}-\lambda_{h} L_{h}\right]
$$

The first order conditions for the above maximization are follows.

$$
\begin{aligned}
& V_{h}: \quad c_{h}=\psi \mu_{h} \theta_{h}^{\delta_{h}-1} \\
& L_{h}: \quad w_{h}+\psi \lambda_{h}=\gamma A L_{h}^{\gamma-1}+\dot{\psi}-\rho \psi
\end{aligned}
$$

In steady-state $\dot{\psi}=0$, therefore, (7) and (8) imply

$$
\gamma A L_{h}^{\gamma-1}=w_{h}+\frac{(\rho+\lambda) c_{h}}{\mu_{h} \theta_{h}^{\delta_{h}-1}}
$$

upon request. The possibility of offshoring reducing unemployment exists even in the efficient bargaining approach where firms and unions simultaneously choose the efficient levels of employment and wages. 
The above equation determines employment $L_{h}$ as a function of $w_{h}$ and $\theta_{h}$. Note that a higher $w_{h}$ demanded by the union results in a lower employment, $L_{h}$.

\section{Wage Determination by Unions}

As mentioned earlier, wages are proposed by unions in the first stage. Following a common practice in the literature, we assume that unions maximize the surplus (or the rent) of their members. While employed workers get a wage of $w_{h}$, unemployed workers get $b_{h}$. Recall from the earlier discussion that workers have access to a traditional technology that allows them to produce $b_{h}$ amount of final good. Implicitly we are assuming that unemployed workers are able to engage in production using this technology. Alternatively, $b_{h}$ can be viewed as the sum of unemployment benefits and the monetary equivalent of the value of leisure of unemployed workers. Later we will use changes in $b_{h}$ to capture the changes in unemployment benefits.

Denote the asset value of an employed worker by $E_{h}$ and the asset value of an unemployed worker by $U_{h}$. These asset values are given in flow terms as follows.

$$
\begin{aligned}
\rho E_{h} & =w_{h}+\lambda_{h}\left(U_{h}-E_{h}\right) \\
\rho U_{h} & =b_{h}+\mu_{h} \theta_{h}^{\delta_{h}}\left(E_{h}-U_{h}\right)
\end{aligned}
$$

The above two imply that

$$
\begin{aligned}
\rho E_{h} & =\frac{\left(\rho+\mu_{h} \theta_{h}^{\delta_{h}}\right) w_{h}+\lambda_{h} b_{h}}{\rho+\lambda_{h}+\mu_{h} \theta_{h}^{\delta_{h}}} \\
\rho U_{h} & =\frac{\mu_{h} \theta_{h}^{\delta_{h}} w_{h}+\left(\rho+\lambda_{h}\right) b_{h}}{\rho+\lambda_{h}+\mu_{h} \theta_{h}^{\delta_{h}}}
\end{aligned}
$$

If the total number of union members is $\bar{L}_{h}$ and $L_{h}$ of them become employed, then the expected welfare of a union member is given by

$$
\left(\frac{\bar{L}_{h}-L_{h}}{\bar{L}_{h}}\right) \rho U_{h}+\left(\frac{L_{h}}{\bar{L}_{h}}\right) \rho E_{h}
$$

If the firm rejects the union's wage offer then all members get their unemployment income $\rho U_{h}$. Therefore, the union's objective is to maximize the aggregate surplus or rent of its members given by

$$
\left(\left(\frac{\bar{L}_{h}-L_{h}}{\bar{L}_{h}}\right) \rho U_{h}+\left(\frac{L_{h}}{\bar{L}_{h}}\right) \rho E_{h}-\rho U_{h}\right) \bar{L}_{h}=\rho\left(E_{h}-U_{h}\right) L_{h}=\frac{\rho\left(w_{h}-b_{h}\right) L_{h}}{\rho+\lambda_{h}+\mu_{h} \theta_{h}^{\delta_{h}}}
$$


where the last equality follows from (12) and $(13)^{12}$.

The subgame perfect equilibrium where the union proposes a wage first and then the firm decides on employment can be obtained by maximizing (15) subject to (9). It is shown in the appendix that the solution to the above problem yields the following expression for wage.

$$
w_{h}=b_{h}+\gamma(1-\gamma) A L_{h}^{\gamma-1}
$$

Next, if the total amount of labor available in Home is $\bar{L}_{h}$, then it must be the case that in equilibrium $\bar{L}_{h}\left(1-u_{h}\right)=L_{h}$. Using the expression for $u_{h}$ in (4) we get

$$
\bar{L}_{h}\left(\frac{\mu_{h} \theta_{h}^{\delta_{h}}}{\lambda_{h}+\mu_{h} \theta_{h}^{\delta_{h}}}\right)=L_{h}
$$

Therefore, the key endogenous variables in an autarky equilibrium, $\theta_{h}, w_{h}$, and $L_{h}$ are determined by (9), (16), and (17). The existence and uniqueness of autarky equilibrium is established in the appendix.

\section{Offshoring Equilibrium for a Small Country}

Now assume that the intermediate input can be imported from abroad at a price of $p_{f}$. There are costs associated with making the imported input work in the domestic production process. We can think of it as the cost of adapting the foreign produced input to the domestic production process. We assume that to use $M$ units of the foreign produced input in the domestic production process, an amount $\phi h(M) M$ must be imported, where $\phi h(M)>1$ and $h^{\prime}(M)>0$. Therefore, the effective per unit cost of the imported input is $p_{f} \phi h(M)$. The restriction $h^{\prime}(M)>0$ captures in a reduced form sense the fact that some inputs may be harder/costlier to offshore than others as in Grossman and Rossi-Hansberg (2008). In our setting it ensures that the firm faces an upward sloping supply curve for the imported input, and yields an interior solution even though domestic and foreign produced inputs are perfect substitutes in efficiency units. The parameter $\phi$ captures the general cost of offshoring arising from costs related to communications barriers, legal restrictions, cultural differences, trade barriers etc. and will be useful in comparative statics below. In ensuing discussions we will call $\phi$ the "offshoring cost"

\footnotetext{
${ }^{12}$ Effectively the union is maximizing the surplus (or rent) of employed members (as in Felbermayr et al.(2008)) since unemployed members don't earn a rent.
} 
and $h(M)$ the "adaptation cost". In the small country case $p_{f}$ is exogenous, but in the two country case discussed later $p_{f}$ is going to be endogenously determined.

We solve the offshoring equilibrium as follows. The representative firm takes $w_{h}, \theta_{h}$, and $p_{f}$ as given and chooses its employment and the extent of offshoring optimally in the second stage. As in autarky, the representative union chooses a wage in the first stage.

For given $w_{h}(s), \theta_{h}(s)$, and $p_{f}$, the firm maximizes the following objective function in the second stage.

$$
\underset{V_{h}(s), L_{h}(s), M(s)}{\operatorname{Max}} \int_{t}^{\infty} e^{-\rho(s-t)}\left\{A\left(L_{h}(s)+M(s)\right)^{\gamma}-w_{h}(s) L_{h}(s)-p_{f} \phi h(M) M(s)-c_{h} V_{h}(s)\right\} d s
$$

subject to the labor adjustment equation (5). Dropping the time notation $s$, the current value Hamiltonian in this case is given by

$$
H=A\left(L_{h}+M\right)^{\gamma}-w_{h} L_{h}-p_{f} \phi h(M) M-c_{h} V_{h}+\psi\left[\mu_{h} \theta_{h}^{\delta_{h}-1} V_{h}-\lambda_{h} L_{h}\right]
$$

The first order conditions are

$$
\begin{aligned}
M & : \gamma A\left(L_{h}+M\right)^{\gamma-1}=p_{f} \phi\left(h(M)+h^{\prime}(M) M\right) \\
V_{h} & : \quad c_{h}=\psi \mu_{h} \theta_{h}^{\delta_{h}-1} \\
L_{h} & : \quad w_{h}+\psi \lambda_{h}=\gamma A\left(L_{h}+M\right)^{\gamma-1}+\dot{\psi}-\rho \psi
\end{aligned}
$$

Again, in steady-state $\dot{\psi}=0$, and therefore, (19) and (20) imply

$$
\gamma A\left(L_{h}+M\right)^{\gamma-1}=w_{h}+\frac{\left(\rho+\lambda_{h}\right) c_{h}}{\mu_{h} \theta_{h}^{\delta_{h}-1}}
$$

Next, (18) and (21) imply

$$
\begin{aligned}
& L_{h}=0 \text { and } M>0 \text { if } \gamma A(M)^{\gamma-1}=p_{f} \phi\left(h(M)+M h^{\prime}(M)\right)<w_{h}+\frac{\left(\rho+\lambda_{h}\right) c_{h}}{\mu_{h} \theta_{h}^{\delta_{h}-1}} \\
& M=0 \text { and } L_{h}>0 \text { if } \gamma A\left(L_{h}\right)^{\gamma-1}=w_{h}+\frac{\left(\rho+\lambda_{h}\right) c_{h}}{\mu_{h} \theta_{h}^{\delta_{h}-1}}<p_{f} \phi h(0)
\end{aligned}
$$

We assume that parameters are such that we always get an interior solution. In that case, equations (18) and (21) determine $L_{h}$ and $M$ for given values of $w_{h}, \theta_{h}$, and $p_{f}$. 


\subsection{Determination of wage in offshoring equilibrium}

The offshoring equilibrium wage is obtained by maximizing the union's objective function, (15), subject to (18) and (21). It is shown in the appendix that the equilibrium wage is given by

$$
w_{h}=b_{h}+\frac{L_{h}\left((1-\gamma) \gamma A\left(L_{h}+M\right)^{\gamma-2} p_{f} \phi\left(2 h^{\prime}(M)+M h^{\prime \prime}(M)\right)\right)}{(1-\gamma) \gamma A\left(L_{h}+M\right)^{\gamma-2}+p_{f} \phi\left(2 h^{\prime}(M)+M h^{\prime \prime}(M)\right)}
$$

The 4 equations (18), (21), (24) along with (17) determine the 4 endogenous variables- $w_{h}, \theta_{h}, L_{h}$ and $M$-in an offshoring equilibrium. Comparing autarky with the offshoring equilibrium, we derive the following analytical result (proved in the online appendix $)^{13}$.

Proposition 1 Offshoring costs that lead equilibrium offshoring to be approximately zero nonetheless reduce both wages and unemployment in the offshoring equilibrium relative to autarky.

As mentioned in the introduction, the mere possibility of offshoring leads to a reduction in the wages demanded by unions which increases the hiring of domestic workers by firms. An implication is that the actual amount of offshoring may hide the true impact of offshoring on labor market outcomes.

\subsection{Comparative Statics with respect to cost of offshoring}

A change in $\phi$ in our model captures the exogenous change in the cost of offshoring. For a linear adaptation cost, $h(M)=d+g M$, we prove the following result in the online appendix. ${ }^{14}$

Proposition 2 In an offshoring equilibrium the wage is monotonically increasing and the extent of offshoring is monotonically decreasing in the cost of offshoring, $\phi$. The rate of unemployment is nonmonotonic in $\phi$. Starting in the vicinity of autarky equilibrium $(M \approx 0)$, a decrease in $\phi$ leads to a decrease in unemployment first but beyond a point unemployment starts increasing as $\phi$ decreases further.

The intuition behind the non-monotonicity of unemployment with respect to the offshoring cost can be understood as follows. Upon a decrease in the offshoring cost, unions foresee jobs moving abroad,

\footnotetext{
${ }^{13}$ The proofs of all the propositions are gathered in an online appendix available at http://www.economics.uci.edu/ pranjan

${ }^{14}$ The analytical proof of non-monotonicity of unemployment is given for $d=0$ case.
} 
and therefore, moderate their wage demands. This moderation of wage demand leads to more hiring of domestic workers as long as the offshoring cost is relatively high. That is, firms can do more of both: offshoring and hiring of domestic workers. However, beyond a point the offshoring cost becomes so low that it makes sense to substitute offshored input for domestic workers, leading to an increase in domestic unemployment.

Even though the result above is proved analytically for the linear adaptation cost case, numerical calibrations discussed below using convex and concave functions provide similar results.

\subsection{Comparative Statics with respect to labor market policies}

As mentioned earlier, a change in $b_{h}$ is used to capture the impact of changes in unemployment benefits. A change $c_{h}$ captures the change in recruitment cost. The following results are proved in the online appendix.

Proposition 3 Increases in unemployment benefits or recruitment costs increase offshoring, wages, and unemployment.

Intuitively, a higher $b_{h}$ increases the reservation wages of unions which results in higher wage demands and consequently, firms find it profitable to hire less domestic workers and increase offshoring. Increases in the recruitment costs induce firms to post less vacancies and hire less domestic workers which increases unemployment in addition to increasing offshoring. Higher recruitment costs also result in higher wages. Intuitively, higher recruitment costs lower the sensitivity of hiring to wages, and therefore, unions are more willing to trade-off higher wages for lower employment.

The results described in the proposition above are also useful in deriving the implications of changes in labor market institutions in Home in the 2 country extension discussed below.

Next, we contrast the impact of offshoring when wages are determined through collective bargaining with the case when wages are determined through individual bargaining.

\section{$5 \quad$ Offshoring with Individual Wage Bargaining}

Assume that instead of wages being determined by unions, firms enter into individual bargaining with matched workers. It is assumed that the domestic employment as well as the amount of inputs offshored 
is chosen in the first stage correctly anticipating the wages that will be determined through individual bargaining in the second stage.

The representative firm maximizes

$$
\underset{V(s), L_{h}(s), M(s)}{\operatorname{Max}} \int_{t}^{\infty} e^{-\rho(s-t)}\left\{A\left(L_{h}(s)+M(s)\right)^{\gamma}-w_{h}(s) L_{h}(s)-p_{f} \phi h(M) M(s)-c_{h} V(s)\right\} d s
$$

subject to (5).

In doing the firm maximization, an issue to consider is whether the wages determined in the second stage are taken as given by the firm or whether the firm recognizes the impact its employment choice will have on the wages negotiated later. In particular, a relevant issue is whether the breakdown of bargaining with a worker leads to a renegotiation of wages with all workers or not. If it does, then the firm takes this into account while choosing employment in the first stage. In this case there is a feedback effect from the marginal product to the wage setting, first pointed out by Stole and Zwiebel (1996), which results in overhiring by the firm because it recognizes that hiring an extra worker will reduce the marginal product of each worker and therefore, reduce the wage the firm will pay to each worker. Dropping the time notation $s$, the first order condition for employment choice in this case can be written as

$$
\gamma A\left(L_{h}+M\right)^{\gamma-1}-L_{h} \frac{d w_{h}}{d L_{h}}=w_{h}+\frac{\left(\rho+\lambda_{h}\right) c_{h}}{\mu_{h} \theta_{h}^{\delta_{h}-1}}
$$

The term $\frac{d w_{h}}{d L_{h}}$ captures the effect identified by Stole and Zwiebel (1996).

Alternatively, one can think of the wages being bargained by each worker simultaneously with the firm (say a separate representative of the firm) without the possibility of renegotiation. Or, the firm could simply be myopic and ignore the consequences of its first stage employment choice on wage bargaining in the second stage. In this case, the first order condition for employment choice is given by

$$
\gamma A\left(L_{h}+M\right)^{\gamma-1}=w_{h}+\frac{\left(\rho+\lambda_{h}\right) c_{h}}{\mu_{h} \theta_{h}^{\delta_{h}-1}}
$$

The first order condition for the optimal choice of $M$ is same as in the union wage case and is given by

$$
\gamma A\left(L_{h}+M\right)^{\gamma-1}=p_{f} \phi\left(h(M)+M h^{\prime}(M)\right)
$$

Denote the bargaining power of workers in Nash bargaining by $\beta_{h}$. It is shown in the online appendix that the wage equation when the firm recognizes the effect of employment choice on wage bargaining 
is given by

$$
w_{h}=\left(1-\beta_{h}\right) b_{h}+\beta_{h} c_{h} \theta_{h}+L_{h}^{-\frac{1}{\beta_{h}}} \gamma A \int_{0}^{L_{h}}(x+M)^{\gamma-1} x^{\frac{1}{\beta_{h}}-1} d x
$$

To obtain the wage in autarky, simply set $M=0$.

Note from (28) that

$$
L_{h} \frac{d w_{h}}{d L_{h}}=-\frac{1}{\beta_{h}} L_{h}^{-\frac{1}{\beta_{h}}} \gamma A \int_{0}^{L_{h}}(x+M)^{\gamma-1} x^{\frac{1}{\beta_{h}}-1} d x+\gamma A\left(L_{h}+M\right)^{\gamma-1}
$$

Using (29), the first order condition (25) can be written as

$$
\frac{1}{\beta_{h}} L_{h}^{-\frac{1}{\beta_{h}}} \gamma A \int_{0}^{L_{h}}(x+M)^{\gamma-1} x^{\frac{1}{\beta_{h}}-1} d x=w_{h}+\frac{\left(\rho+\lambda_{h}\right) c_{h}}{\mu_{h} \theta_{h}^{\delta_{h}-1}}
$$

Equations (17), (27), (28), and (30) determine the 4 key endogenous variables $L_{h}, M, w_{h}$, and $\theta_{h}$ in an offshoring with individual bargaining.

It is difficult to obtain analytical results on the impact of offshoring in the case above, therefore, we will rely on numerical calibrations. However, in the other case mentioned earlier which obtains when either the firm is myopic or there is no possibility of renegotiation, we can obtain analytical results. It is shown in the online appendix that the wage equation in this case is given by

$$
w_{h}=(1-\beta) b_{h}+\beta_{h} c_{h} \theta_{h}+\beta_{h} \gamma A\left(L_{h}+M\right)^{\gamma-1}
$$

In this case, equations (17), (26), (27), and (31) determine $L_{h}, M, w_{h}$, and $\theta_{h}$ in an offshoring equilibrium with individual bargaining.

The following results on the impact of offshoring under the restriction that the adaptation cost function $h(M)$ is not too concave $\left(2 h^{\prime}(M)+h^{\prime \prime}(M)>0\right)$ are proved in the online appendix.

Proposition 4 When wages are determined through individual Nash bargaining, the wages are always lower and the unemployment is always higher in an offshoring equilibrium compared to the autarky equilibrium. Moreover, the offshoring equilibrium wage is monotonically increasing and unemployment is monotonically decreasing in the cost of offshoring, $\phi$.

In terms of intuition, the key difference in the individual bargaining case comes from the fact that when an individual worker bargains with a firm, all that the worker cares about is his own wage. A decrease in the cost of offshoring does reduce his wage but the worker is not going to accept a deeper wage cut to increase domestic employment. In the case of union wage setting on the other hand, seeing a decrease in the cost of offshoring, unions reduce their wage demands to moderate the impact of offshoring on employment. 


\section{Numerical Calibrations for the small country case}

The country chosen for calibration exercise is Sweden because it is one of the countries where most of the workers are covered by collective bargaining agreements. According to Venn (2009), 92\% of workers in Sweden were covered by collective bargaining agreement. Most of the parameters chosen for our calibration exercise for Sweden are taken from Albrecht et al. (2006) who conduct a calibration exercise to assess the labor market effects of the Swedish knowledge lift program. Since they work with two different types of workers, low and medium skilled, while we have only one type of worker in the model, we construct an aggregate rate of job destruction and exit rate from unemployment based on their disaggregated numbers. We provide details of this exercise as well as the choice of several parameters and their sources in the appendix. Below we discuss the choice of some crucial parameters.

We obtain an estimate of the exit rate from unemployment, $\mu_{h} \theta_{h}^{\delta_{h}}$, of 1.948 based on the numbers in Albrecht et al. (2006). No independent estimates of $\theta_{h}$ are available so, rather than picking $\theta_{h}$ arbitrarily, we use $\theta_{h}=.5$ from Hall (2005). The most commonly used estimate of the elasticity of matching function, $\delta_{h}$, in the literature including that in Albrecht et al. (2006) is 0.5, which is what we use as well. These values of $\theta_{h}$ and $\delta_{h}$ pin down the scale parameter in the matching function, $\mu_{h}$, at 2.755. Alternative values of $\theta_{h}$ provide different values of the scale parameter but results are qualitatively similar. Ekholm and Hakkala (2008) provide several estimates of the extent of offshoring for Sweden. We use one of their measures called the share of imported input in total intermediate consumption (narrow) the value of which for all industries in 1995 is .072. The word narrow refers to the fact that the input is imported within the industry rather than from other industries and may be a more relevant measure for the kind of offshoring we have in mind where the imported inputs are close substitutes for domestically produced inputs. Using their alternative measures of offshoring in our numerical exercise provides qualitatively similar results. Note that the amount of intermediate input produced domestically in our model is given simply by $L_{h}$. Therefore, the ratio of imported inputs to total intermediate consumption in our model is $\frac{M}{L_{h}+M}$. Our baseline calibration sets $\frac{M}{L_{h}+M}=.07$.

We have three remaining parameters: $c_{h}, \phi$, and $p_{f}$ to determine. Recall that $\phi$ in our model captures the general cost of offshoring arising from costs related to communications barriers, legal restrictions, cultural differences, trade barriers etc. A commonly used value of the transportation cost alone in calibration exercises is 1.3 (e.g. Felbermayr et al, 2011). Since $\phi$ includes more than just transportation cost, we choose a slightly higher initial value of $\phi$ at 1.5. The remaining two parameters 
$c_{h}$ and $p_{f}$ are chosen to match the unemployment rate of .077 for 1995 in Sweden and $\frac{M}{L_{h}+M}=.07$. We are going to try 3 alternative specifications of the adaptation cost function $h(M)$ : Linear case : $h(M)=1+M$; Convex Case: $h(M)=(1+M)^{2}$; Concave Case: $h(M)=\sqrt{(1+M)} \cdot{ }^{15}$ Depending on the specification of $h(M)$, we obtain different values of $c_{h}$ and $p_{f}$. In our comparative static exercises, for each specification of the adaptation cost function, we hold the values of $c_{h}$ and $p_{f}$ constant at their respective baseline values.

Figure 1 shows the results of comparative statics with respect to the offshoring cost parameter $\phi$ when $h(M)=1+M$. The horizontal line in each figure shows the hypothetical autarky value of the variable of interest. Figure 1a shows the non-monotonicity of unemployment with respect to $\phi$. The horizontal line drawn from the right axis at .099 shows the hypothetical autarky unemployment for the baseline parameter values (to show the non-monotonicity of unemployment clearly, we have drawn the horizontal line from right axis in Figure 1a). That is, Figure 1a says that if Sweden were a closed economy, then with these parameter values its unemployment rate would be $9.9 \%$ instead of it being $7.7 \%$. The highest value of $\phi$ in this figure is at 1.75 . At this value of $\phi, M$ becomes zero. That is, even though Sweden is notionally open, the offshoring cost is so high that offshoring becomes zero. The unemployment at this value of $\phi$ is $7.85 \%$. The fact that the hypothetical autarky unemployment of $9.9 \%$ is greater than the offshoring equilibrium unemployment of $7.85 \%$ when $\phi=1.75$ and consequently, $M=0$ is consistent with the result described in proposition 1 with respect to unemployment. Figure 1b shows that the wage in Sweden decreases as the offshoring cost decreases. The gap between the horizontal line and the downward sloping line at $\phi=1.75$ is consistent with the result on wages in proposition 1.

Figures $1 \mathrm{c}$ and $1 \mathrm{~d}$ show the impact of offshoring on unemployment and wages in the case of individual bargaining. These figures are drawn using a value of workers' bargaining power, $\beta_{h}$, of 0.5 . Again, the free parameters $c_{h}$ and $p_{f}$ are chosen to yield $u_{h}=.077$ and $\frac{M}{L_{h}+M}=.07$ when $\phi=1.5$. The horizontal lines capture the hypothetical autarky values. In both figures $1 \mathrm{a}$ and 1c, the value of unemployment in an offshoring equilibrium corresponding to $\phi=1.5$ is 0.077 by construction. It is easily seen from figures $1 \mathrm{c}$ and $1 \mathrm{~d}$ that a decrease in the offshoring cost leads to an increase in unemployment and a

\footnotetext{
${ }^{15}$ In reality, the adaptation cost would vary across industries and would capture the ease/difficulty of offshoring inputs/tasks. A convex adaptation cost would capture an industry where relatively little can be offshored while a concave adaptation cost would capture the opposite case of an industry where it is easy to offshore most inputs.
} 
decrease in wage. As well, offshoring equilibrium unemployment is always higher and wages are lower than in the autarky equilibrium which is consistent with proposition 4 .

One way to look at the quantitative significance of collective bargaining in determining labor market outcomes is to note from figures $1 \mathrm{a}$ and $1 \mathrm{c}$ that an increase in the offshoring cost from $\phi=1.5$ to $\phi=1.75$ increases unemployment by 0.185 percentage points with collective bargaining, but the same increase in the offshoring cost reduces unemployment by 0.5 percentage points in the case of individual bargaining, a difference of 0.7 percentage points.

Figures 2 and 3 repeat the same exercise for convex and concave $h(M)$ functions, respectively. To highlight the non-monotonicity of unemployment with respect to offshoring costs, depending on the specification of $h(M)$, we choose different minimum values of $\phi: 0.5$ in figure 2 and 1 in figure 3 . As well, in figures $2 \mathrm{a}$ and $3 \mathrm{a}$, again the right axis is used to depict the hypothetical autarky value of unemployment. The qualitative results in figures 2 and 3 are similar to those in figure 1 . It is worth pointing out that even though offshoring increases in response to a decrease in $\phi$, the reduction in $\phi$ is partially offset by an increase in the adaptation cost due to $h^{\prime}(M)>0$. This latter effect is stronger the more convex the adaptation cost, and therefore, a given reduction in $\phi$ leads to a smaller increase in offshoring the more convex the adaptation cost. An implication is that the range of $\phi$ over which unemployment decreases is larger the more convex the adaptation cost.

\subsection{Numerical results with CES production function}

In the baseline model it was assumed that the input produced by domestic labor and the offshored input were perfect substitutes once the latter were adapted. However, our results hold more generally when the substitutability between domestic labor and offshored input is high. We confirm this numerically using the constant elasticity of substitution (CES) production function of the following form.

$$
Z=A\left(L_{h}^{\frac{\sigma-1}{\sigma}}+M^{\frac{\sigma-1}{\sigma}}\right)^{\frac{\sigma \gamma}{\sigma-1}} ; \sigma>0
$$

where $\sigma$ is the elasticity of substitution between domestic labor and the offshored input. To conserve space, the equations for the CES production function case are presented in the online appendix. The results of the numerical calibrations using the CES production function are shown in figure 4 which assumes a linear adaptation cost: $h(M)=1+M$. Figure 4a shows the relationship between unemployment and offshoring cost, $\phi$, for $\sigma=10$, when wages are determined through collective bargaining. We 
again obtain a non-monotonic relationship between unemployment and $\phi$ similar to the one obtained for the perfect substitute case in figure 1a. We have verified that as $\sigma \rightarrow \infty$ the results converge to those in figure 1a. One difference between figure $1 \mathrm{a}$ and figure $4 \mathrm{a}$ is that for $\phi \geq 1.75$, offshoring becomes zero $(M=0)$ in figure 1a and therefore, unemployment becomes delinked from the offshoring cost for $\phi \geq 1.75$. In the imperfect substitute case drawn in figure 4a, offshoring goes to zero only in the limit as $\phi \rightarrow \infty$ and therefore, the offshoring unemployment rate keeps increasing and asymptotes a horizontal line as $\phi \rightarrow \infty$. Figure $4 \mathrm{~b}$ is drawn for the case of $\sigma=4$ where again a non-monotonic relationship obtains between the cost of offshoring and unemployment. Figures $4 \mathrm{~d}$ and $4 \mathrm{e}$ are the analogues of figures $4 \mathrm{a}$ and $4 \mathrm{~b}$ for the individual bargaining case. As was the case in figures 1-3, with individual bargaining, a decrease in the cost of offshoring leads to an increase in unemployment.

It was mentioned earlier that if there is a high degree of complementarity between the offshored input and domestic labor (as in the model of Grossman and Rossi-Hansberg (2008)), then greater offshoring can lead to lower unemployment even with individual bargaining. In our model the complementarity effect becomes stronger as $\sigma$ declines. Figure 4c plots the relationship between offshoring and unemployment for $\sigma=2.5$ for the collective bargaining case ${ }^{16}$. Due to the complementarity, an increase in offshoring (induced by lower $\phi$ ) leads to a decrease in unemployment. And finally, as mentioned in the introduction, figure $4 \mathrm{f}$ shows that greater offshoring is associated with reduced unemployment even in the case of individual bargaining when $\sigma=2.5$.

Therefore, we claim that the result that we derived on the non-monotonic relationship between offshoring and unemployment in the collective bargaining case when domestic labor and offshored input are perfect substitutes holds more generally for high elasticity of substitution between the two inputs.

\section{Offshoring in a two country world}

Now, we discuss the two country case where the price of the offshored input, $p_{f}$, is determined endogenously. Assume that one unit of Foreign labor can produce one unit of the intermediate input. The

\footnotetext{
${ }^{16}$ All the parameters used to draw figures $4 \mathrm{c}$ and $4 \mathrm{f}$ are the same as in figures $1-3$, and $4 \mathrm{a}, 4 \mathrm{~b}, 4 \mathrm{~d}, 4 \mathrm{e}$, except for one: $b_{h}$. In the baseline case we used a value of $b_{h}$ that gave a replacement rate of $67 \%$. It turns out that for this value of $b_{h}$, the implied $c_{h}$ when $\sigma=2.5$ becomes negative in the collective bargaining case. Therefore, we used a value of $b_{h}$ such that the replacement rate is $50 \%$.
} 
alternative for Foreign labor is to produce $b_{f}$ units of the final good using a traditional technology. We also assume that the wages in the production of the intermediate good in Foreign are determined through individual Nash bargaining and not collective bargaining. ${ }^{17}$ Since Foreign does not have the sophisticated technology to produce the final good, and there is constant returns to scale in the production of the intermediate good, there is no loss of generality in assuming that Foreign has one worker firms.

With one worker firms, if the price of the intermediate input is $p_{f}$, the value of output produced by one unit of labor is $p_{f}$. Since firms have to post vacancies and pay workers a wage of $w_{f}$, free entry in vacancy creation implies the following.

$$
p_{f}=w_{f}+\frac{\left(\rho+\lambda_{f}\right) c_{f}}{\mu_{f} \theta_{f}^{\delta_{f}-1}}
$$

Assume the bargaining power of workers to be $\beta_{f}$. Following the same steps as in the case of Home, it is shown in the appendix that the wage determined through Nash bargaining in Foreign is

$$
w_{f}=\left(1-\beta_{f}\right) b_{f}+\beta_{f}\left(p_{f}+c_{f} \theta_{f}\right)
$$

The above two equations determine $w_{f}$ and $\theta_{f}$ for each $p_{f}$. It can be verified that (32), which is commonly referred to as the Job Creation (JC) condition in the search literature, implies a downward sloping relationship between $w_{f}$ and $\theta_{f}$. (33), referred to as the Wage Bargaining (WB) condition, implies an upward sloping relationship between $w_{f}$ and $\theta_{f}$. The intersection of these two relationships determines $w_{f}$ and $\theta_{f}$ for a given $p_{f}$ as is shown in Figure 5a. Once we know $\theta_{f}$ we can find out the amount of labor employed in this sector, which also equals the output of the intermediate good produced by Foreign, from the equation below.

$$
\bar{L}_{f}\left(1-u_{f}\right)=\bar{L}_{f}\left(\frac{\mu_{f} \theta_{f}^{\delta_{f}}}{\lambda_{f}+\mu_{f} \theta_{f}^{\delta_{f}}}\right)=L_{f}
$$

where $u_{f}$ is the rate of unemployment in Foreign. Therefore, for each $p_{f}$ we obtain the supply of the intermediate input produced in Foreign from the 3 equations (32), (33), and (34) above. An increase in $p_{f}$ shifts both the JC and the WB curves up in Figure 5a. It can be verified from (32) and (33) that

\footnotetext{
${ }^{17}$ It is possible for the wages in Foreign also to be determined by collective bargaining. However, to avoid discussing too many cases, we restrict the wage determination in Foreign to individual bargaining.
} 
the vertical shift in the JC curve is more than the vertical shift in the WB curve. Therefore, both $w_{f}$ and $\theta_{f}$ increase. An increase in $\theta_{f}$, in turn, implies from (34) that the supply of the intermediate input from Foreign increases. Therefore, the supply curve for the intermediate input produced in Foreign is upward sloping.

The demand for the intermediate input produced in Foreign comes from Home. The demand curve can be derived from the 4 equations, (17), (18), (21), (24), which give $L_{h}, \theta_{h}, w_{h}$, and $M$ for a given $p_{f}$ for Home. Recall that in the small open economy case we had shown that $\frac{d M}{d \phi}<0$. Since $\phi$ and $p_{f}$ are isomorphic in the small open economy case, it follows that $\frac{d M}{d p_{f}}<0$. Note that when firms in Home use $M$ amount of the offshored input, the amount actually purchased from Foreign is $\phi h(M) M$ given that some of the Foreign produced input is lost in the adaptation process. Since $h^{\prime}(M)>0$, it is easily verified that

$$
\frac{d(\phi h(M) M)}{d p_{f}}=\phi\left(h(M)+h^{\prime}(M) M\right) \frac{d M}{d p_{f}}<0
$$

Therefore, the demand curve for the gross amount of offshored input, $\phi h(M) M$, is decreasing in $p_{f}$. Since the demand is downward sloping and the supply is upward sloping, there exists a price $p_{f}$ that clears the market for the intermediate input produced in Foreign as shown in Figure 5b. Algebraically, the price $p_{f}$ is determined by the following market clearing condition for the input produced in Foreign:

$$
L_{f}=\phi h(M) M
$$

The offshoring equilibrium in a two country world is characterized by the 8 equations (17), (18), (21), (24), (32), (33), (34) and (36), which solve for the 8 endogenous variables of interest: $L_{h}, M, w_{h}, \theta_{h}, L_{f}, w_{f}, p_{f}$, and $\theta_{f}$.

\subsection{Comparative Statics}

\subsubsection{Decrease in the cost of offshoring}

Starting from an offshoring equilibrium, holding the price of the offshored input constant, a decrease

in the cost of offshoring, $\phi$, increases the amount of offshored input used in Home: $\frac{\partial M}{\partial \phi}<0$. What happens to the price, $p_{f}$, depends on what happens to the amount of input purchased from Foreign, $\phi h(M) M:$

$$
\frac{\partial(\phi h(M) M)}{\partial \phi}=h(M) M+\phi\left(h(M)+h^{\prime}(M) M\right) \frac{\partial M}{\partial \phi}
$$


There are two effects of a decrease in the cost of offshoring. Since offshoring becomes more attractive firms want to offshore more. However, a decrease in $\phi$ also reduces the amount of the Foreign produced input that needs to be purchased for any given amount used in the production process. A sufficient condition for $\frac{\partial(\phi h(M) M)}{\partial \phi}<0$ is

$$
\left|\frac{\phi}{M} \frac{\partial M}{\partial \phi}\right|>\frac{h(M)}{\left(h(M)+h^{\prime}(M) M\right)}
$$

We will assume that this condition is satisfied, that is, the first effect mentioned above dominates. Numerical simulations using the parameters used in Figures 1-3 confirm that $\frac{\partial(\phi h(M) M)}{\partial \phi}<0$ for the three cases of the adaptation cost. The results are shown in figure 6. When (38) is satisfied, we get the reasonable result that a decrease in the offshoring cost increases the demand for the intermediate input produced in Foreign. That is, the demand curve in Figure 5b shifts to the right. Since nothing happens to the supply curve, there is an increase in the price, $p_{f}$. An implication is that Foreign is going to export more of the intermediate input.

An increase in $p_{f}$ implies from Figure 5a that unemployment decreases and wages increase in Foreign. The impact on Home labor market depends on two effects: a direct effect of a decrease in $\phi$ which is same as in the small country case and a feedback effect arising from an increase in $p_{f}$. Whether the feedback effect completely offsets or partially offsets the direct effect depends on the parameters and can be answered only in specific cases ${ }^{18}$. Figure 7 provides an illustration of the numerical relationship between offshoring and unemployment when $p_{f}$ is endogenous. To construct figure 7 we need to specify parameters for Foreign. To avoid using too many new parameters in the two country case, we continue to use the parameters for Sweden for Home. For Foreign we arbitrarily choose the parameters, some of them same as in Sweden, so that the baseline two country case reproduces the baseline result for Sweden. The parameters for Foreign are listed in the appendix. For all 3 cases of the adaptation cost, the results with endogenous $p_{f}$ in figure 7 are similar to those with exogenous $p_{f}$ in figures $1 \mathrm{a}, 2 \mathrm{a}$, and 3a. That is, as is reasonable, the feedback effect from $p_{f}$ is not strong enough to offset the direct effect of a change in $\phi$. We summarize the results in a proposition below.

Proposition 5 Decreases in the cost of offshoring in a two county world increase offshoring and wages and reduce unemployment in Foreign, the source country. The impact on Home, the host country, labor market is qualitatively similar to that in the small country case.

\footnotetext{
${ }^{18}$ The increase in $p_{f}$ in Home is similar to the terms of trade loss arising from a tariff reduction in a large country.
} 
It is worth re-iterating that the non-monotonicity of Home unemployment in the offshoring cost obtains even in a two country setting when the price of the offshored input is endogenously determined.

\subsubsection{Changes in Foreign Labor Market Institutions}

We study the impact of changes in unemployment benefits or recruitment costs in Foreign on the labor markets in both Home and Foreign. Note that we have described $b_{f}$ as the amount of final good that a worker can produce using traditional technology. As with $b_{h}$ discussed earlier, we interpret $b_{f}$ broadly to include unemployment benefits as well. In that case, an increase in $b_{f}$ can be used to capture increases in the unemployment benefits. In all these cases, the impact on Home labor market works through changes in $p_{f}$. Therefore, we need to figure out how the supply of the intermediate input by Foreign changes in response to changes in its labor market policies.

An increase in $b_{f}$ shifts the upward sloping WB curve to the left leaving the downward sloping curve JC curve unaffected in Figure 5a. This leads to a decrease in $\theta_{f}$ and an increase in $w_{f}$. A decrease in $\theta_{f}$ implies a decrease in the supply of the intermediate input produced by Foreign. Since the demand from Home is unchanged, there is an increase in the price, $p_{f}$. Therefore, the impact of an increase in $b_{f}$ on Home is similar to that of an increase in $\phi$ described in proposition 2. That is, unemployment may increase in Home in the presence of collective bargaining. ${ }^{19}$ The impact on Foreign consists of a direct effect and a feedback effect arising from an increase in $p_{f}$. Since the feedback effect on wages is in the same direction as the direct effect, wages increase unambiguously. The direct effect of an increase in $b_{f}$ is to increase unemployment, but the feedback effect from the induced increase in $p_{f}$ reduces unemployment, rendering the net effect theoretically ambiguous. The impact of an increase in $\beta_{f}$, the bargaining power of Foreign workers, is qualitatively similar to the impact of an increase in $b_{f}$.

An increase in the recruitment cost, $c_{f}$, leads to a leftward shift in both JC and WB curves in Figure 5a. Therefore, $\theta_{f}$ decreases unambiguously. It is verified in the online appendix that $w_{f}$ decreases as well. A decrease in $\theta_{f}$ implies a decrease in the supply of the intermediate input produced by Foreign leading to an increase in $p_{f}$. Since $p_{f}$ increases, the impact on Home as the result described in proposition 2. In Foreign the direct effect of an increase in $c_{f}$ is decreased wages and increased unemployment, however, the feedback effects arising from an increase in $p_{f}$ go in the opposite direction rendering the net effect ambiguous.

\footnotetext{
${ }^{19}$ In the presence of individual bargaining in Home, however, unemployment decreases unambiguously.
} 
We summarize the results below.

Proposition 6 Increases in unemployment benefits or recruitment costs in Foreign lead to less offshoring by Home. Home wages increase, but the impact on Home unemployment is theoretically ambiguous. Foreign wages increase with unemployment benefits, but the impact on Foreign unemployment is ambiguous. Increases in recruitment costs have ambiguous effects on Foreign wages and unemployment.

\subsubsection{Changes in Home Labor Market Institutions}

As mentioned in proposition 3 for the small country case, increases in $b_{h}$ or $c_{h}$ increase offshoring for a given $p_{f}$. That is, they increase the demand for the offshored input and therefore, the demand curve in figure $5 \mathrm{~b}$ shifts to the right. Since the supply curve of Foreign is unchanged, the price, $p_{f}$, of the Foreign produced input increases. The consequence for Foreign is increased wages and reduced unemployment. The impact on Home labor market consists of a direct effect discussed in proposition 3 and a feedback effect coming from an increase in $p_{f}$. The impact of an increase in $p_{f}$ is the same as that of an increase in $\phi$ discussed in proposition 2. That is, Home wages increase, but Home unemployment changes nonmontonically with respect to $p_{f}$. The net result is that Home wages increase unambiguously, but the impact on Home unemployment is ambiguous. The results are summarized below.

Proposition 7 Increases in recruitment costs or unemployment benefits in Home increase offshoring by Home. Foreign experiences increased wages and reduced unemployment. Home wages increase but the impact on Home unemployment is ambiguous.

The results summarized in propositions 6 and 7 show the importance of labor market institutions in a globalized world. Lower unemployment benefits or recruitment costs in host countries give them an advantage in producing offshored inputs and therefore lead to greater offshoring with attendant consequences for the labor markets in source countries. Similarly, higher unemployment benefits or recruitment costs in source countries lead to greater offshoring which improve the labor market outcomes in host countries, but have ambiguous effects on unemployment in source countries. 


\section{Concluding Remarks}

This paper shows the crucial role of labor market institutions in determining the impact of globalization on unemployment and wages. In particular, it shows how the results differ across alternative wage setting institutions such as individual bargaining and collective bargaining. While a model with individual bargaining predicts that offshoring would increase unemployment, we show that it can go down if wages are determined through collective bargaining. The calibration exercise using parameters for Sweden verifies the non-monotonic relationship between the cost of offshoring and unemployment. Moreover, it predicts that a decrease in the cost of offshoring starting from the present level would reduce unemployment in Sweden. Extending the model to a two country set up allows us to study how labor market institutions in one country have spillover effects on its trading partner. In particular, increases in the recruitment costs or unemployment benefits in the host country can increase unemployment in both the host and the source country. Increases in recruitment costs or unemployment benefits in the source country, on the other hand, are likely to increase unemployment in the source country, but reduce unemployment in the host country. An implication is that when thinking about labor market policies in open economies, the policymakers have to be mindful of the feedback effects of policies working through forces of globalization. For example, a more generous unemployment benefit in Home not only increases unemployment in Home directly as would be the case in a closed economy, but also leads to increased offshoring. Increased offshoring leads to an increase in the price of imported input, which can lead to further increases in unemployment if wages are determined by collective bargaining. Therefore, the impact of changes in labor market policies may be magnified in a globalized world.

Finally, while we have focused on the competitive threats from offshoring in this paper, similar considerations may be present within a country from its internal geography. For example, the possibility of jobs moving from a high wage region to a low wage region can have similar consequences for unemployment in the two regions as in our two country setting. We focus on offshoring for a couple of reasons: One, the wage differences within a country are usually smaller than across countries; Two, the impact of offshoring on aggregate unemployment for a country is likely to be much larger than from the movement of jobs from one region within a country to another, although in the latter case it could give rise to severe inter-regional differences in unemployment rates. 


\section{References}

[1] Antras, P. and Helpman, E., 2004. "Global Sourcing," Journal of Political Economy 112(3), 552580.

[2] Albrecht, J. G J. van den Berg, and S. Vroman (2006). "The Aggregate Labor Market Effects of the Swedish Knowledge Lift Program", IZA working paper \#2385.

[3] Bentolila, S. and Gilles Saint-Paul. 2003. "Explaining Movements in the Labor Share", Contributions to Macroeconomics, BE press, Volume 3, Issue 1.

[4] Blinder, A.S. 2009. "How many U.S. Jobs Might be Offshorable", World Economics, vol. 10, no.2.

[5] Braun, S. and J. Scheffel. 2007. Does International Outsourcing Depress Union Wages? SFB 649 Discussion Paper 2007-033.

[6] Brock, Ellen and Sabien Dobbelaere (2006). "Has International Trade Affected Workers' Bargaining Power?" Review of World Economics, 142(2): 233:266.

[7] Cahuc, Pierre and Zylberberg, Andre (2004). Labor Economics. MIT Press, Cambridge, MA.

[8] Davidson, C. and Matusz, S., 2004. International trade and labor markets. WE Upjohn Institute of Employment Research, Kalamazoo, Michigan.

[9] Davidson, C., Matusz, S., Shevchenko, A., 2008. Outsourcing Peter to pay Paul: High-skill Expectations and low-skill Wages and imperfect labor markets. Macroeconomic Dynamics, September, 463-479.

[10] Davis, D.(1998). 'Does European unemployment prop up American wages? National labour markets and global trade', American Economic Review, vol. 88, pp.478-94.

[11] Delacroix, A. 2006. "A Multisectorial matching model of unions", Journal of Monetary Economics, $53,573-596$.

[12] Dumont, Michel, Glenn Rayp and Peter Willeme (2006). "Does Internationalisation Affect Union Bargaining Power? An Empirical Study for Five EU-Countries." Oxford Economic Papers. 58( ): $77-102$. 
[13] Ebenstein A, Harrison A, McMillan M, Phillips S. 2009. "Estimating the impact of trade and offshoring on American workers using the current population surveys". NBER Work. Pap. 15107

[14] Ekholm, K. and K. Nilsson. Hakkala. (2008). "The Effect of Offshoring on Labor Demand: Evidence from Sweden", working paper, Department of Economics, Stockholm University.

[15] Felbermayr, G., Prat, J., \& Schmerer, H. (2008). Globalization and Labor Market Outcomes: Wage Bargaining, Search Frictions, and Firm Heterogeneity. IZA working paper \#3363, IZA, Bonn.

[16] Felbermayr, G., Larch, M. and Lechthaler, Wolfgang. (2009). "Unemployment in an interdependent world", CESifo working paper number 2788.

[17] Felbermayr, G., Prat, J., \& Schmerer, H. (2011). Globalization and Labor Market Outcomes: Wage Bargaining, Search Frictions, and Firm Heterogeneity. Journal of Economic Theory, 146(1), 39-73.

[18] Grossman, G. and Rossi-Hansberg, E., 2008. Trading tasks: A simple theory of offshoring. American Economic Review 98(5), 1978-97.

[19] Harrison, A., McLaren, John, and Margaret McMillan. 2011. "Recent Perspectives on Trade and Inequality" , Annual Review of Economics, vol. 3, 261-289.

[20] Helpman, E., 2006. Trade, FDI, and the organization of firms. Journal of Economic Literature 44, 589-630.

[21] Helpman, E. and Oleg Itskhoki. 2010. "Labor Market Rigidities, Trade and Unemployment", Review of Economic Studies, 77 (3): 1100-1137

[22] Helpman, E., Oleg Itskhoki and Stephen Redding. 2010. "Inequality and Unemployment in a Global Economy", Econometrica, July, 78 (4): 1239-1283

[23] Hall, Robert (2005), Employment Fluctuations with Equilibrium Wage Stickiness, American Economic Review, 95(1): 50-65.

[24] Mezzetti, C. and E. Dinopoulos. 1991. "Domestic Unionization and Import Competition", Journal of International Economics, 31. 
[25] Mitra, D. and Ranjan P. 2010. "Offshoring and Unemployment: The Role of Search Frictions and Labor Mobility", Journal of International Economics, 81(2).

[26] Moore, M., Ranjan, P., 2005. Globalization vs skill biased technical change: Implications for unemployment and wage inequality. Economic Journal 115(503), 391-422.

[27] OECD. 1999. OECD Employment Outlook. OECD, Paris.

[28] OECD. 2007. Offshoring and Employment: TRENDS AND IMPACTS. OECD, Paris.

[29] OECD. 2010. OECD Employment Outlook. OECD, Paris.

[30] Pissarides, Christopher A. 1986. Trade Unions and the Efficiency of the Natural Rate of Unemployment, Journal of Labor Economics, Vol. 4, No. 4, pp. 582-595.

[31] Pissarides, Christopher A. (2000), Equilibrium Unemployment Theory, 2nd edition, Cambridge, Mass: MIT Press.

[32] Pissarides, Christopher A., and Barbara Petrongolo (2001), Looking into the black box: A survey of the matching function, Journal of Economic Literature 39: 390-431.

[33] UNCTAD (UN Conference on Trade and Development). 2004. World Investment Report 2004: The Shift Towards Services. Geneva.

[34] Venn, Danielle (2009), "Legislation, collective bargaining and enforcement:Updating the OECD employment protection indicators", www.oecd.org/els/workingpapers 


\section{$9 \quad$ Appendix}

\subsection{Wage Determination in Autarky}

The union maximizes $\frac{\rho\left(w_{h}-b_{h}\right) L_{h}}{\rho+\lambda_{h}+\mu_{h} \theta_{h}^{\delta_{h}}}$ in the first stage, anticipating firms to choose employment given by the condition (9) in the text. The problem is equivalent to maximizing the the following Lagrangian by choosing $w_{h}$ and $L_{h}$.

$$
\Upsilon=\left(\frac{\rho\left(w_{h}-b_{h}\right) L_{h}}{\rho+\lambda_{h}+\mu_{h} \theta_{h}^{\delta_{h}}}\right)+\xi\left[\gamma A L_{h}^{\gamma-1}-w_{h}-\frac{(\rho+\lambda) c_{h}}{\mu_{h} \theta_{h}^{\delta_{h}-1}}\right]
$$

The first order conditions are

$$
\begin{aligned}
& w_{h}:\left(\frac{\rho L_{h}}{\rho+\lambda_{h}+\mu_{h} \theta_{h}^{\delta_{h}}}\right)=\xi \\
& L_{h}:\left(\frac{\rho\left(w_{h}-b_{h}\right)}{\rho+\lambda_{h}+\mu_{h} \theta_{h}^{\delta_{h}}}\right)=\xi(1-\gamma) \gamma A L_{h}^{\gamma-2}
\end{aligned}
$$

Solve the above two to get

$$
w_{h}=b_{h}+(1-\gamma) \gamma A L_{h}^{\gamma-1}
$$

\subsection{Existence and Uniqueness of Autarky Equilibrium}

Using (17) to substitute out $L_{h}$ in (9) and (16) obtain

$$
\begin{aligned}
\gamma A\left(\bar{L}_{h}\left(\frac{\mu_{h} \theta_{h}^{\delta_{h}}}{\lambda_{h}+\mu_{h} \theta_{h}^{\delta_{h}}}\right)\right)^{\gamma-1} & =w_{h}+\frac{\left(\rho+\lambda_{h}\right) c_{h}}{\mu_{h} \theta_{h}^{\delta_{h}-1}} \\
w_{h} & =b_{h}+\gamma(1-\gamma) A\left(\bar{L}_{h}\left(\frac{\mu_{h} \theta_{h}^{\delta_{h}}}{\lambda_{h}+\mu_{h} \theta_{h}^{\delta_{h}}}\right)\right)^{\gamma-1}
\end{aligned}
$$

From (43) and (44) obtain the following equation determining the autarky equilibrium value of $\theta_{h}$.

$$
\gamma^{2} A\left(\bar{L}_{h}\left(\frac{\mu_{h} \theta_{h}^{\delta_{h}}}{\lambda_{h}+\mu_{h} \theta_{h}^{\delta_{h}}}\right)\right)^{\gamma-1}=b_{h}+\frac{\left(\rho+\lambda_{h}\right) c_{h}}{\mu_{h} \theta_{h}^{\delta_{h}-1}}
$$

It is easy to verify that the r.h.s of (45) is increasing in $\theta_{h}$ and has a vertical intercept at $b_{h}$. The l.h.s of (45) is decreasing in $\theta_{h}$, asymptotes the vertical axis as $\theta_{h} \rightarrow 0$ while asymptotes $\frac{\gamma^{2} A}{\bar{L}_{h}^{1-\gamma}}$ as $\theta_{h} \rightarrow \infty$. Therefore, there exists a unique $\theta_{h}$ that solves equation (45). It follows from (43) that there is a unique value of $w_{h}$ in autarky. 


\subsection{Derivation of wage in the offshoring case}

The Lagrangian is given by

$\Upsilon=\left(\frac{\rho\left(w_{h}-b_{h}\right) L_{h}}{\rho+\lambda_{h}+\mu_{h} \theta_{h}^{\delta_{h}}}\right)+\psi\left[\gamma A\left(L_{h}+M\right)^{\gamma-1}-w_{h}-\frac{\left(\rho+\lambda_{h}\right) c_{h}}{\mu_{h} \theta_{h}^{\delta_{h}-1}}\right]+\varphi\left[p_{f} \phi\left(h(M)+M h^{\prime}(M)\right)-w_{h}-\frac{\left(\rho+\lambda_{h}\right) c_{h}}{\mu_{h} \theta_{h}^{\delta_{h}-1}}\right]$

The first order conditions with respect to $w_{h}, L_{h}$, and $M$ are given by

$$
\begin{aligned}
& w_{h}:\left(\frac{\rho L_{h}}{\rho+\lambda_{h}+\mu_{h} \theta_{h}^{\delta_{h}}}\right)=\psi+\varphi \\
& L_{h}: \frac{\rho\left(w_{h}-b_{h}\right)}{\rho+\lambda_{h}+\mu_{h} \theta_{h}^{\delta_{h}}}=\psi(1-\gamma) \gamma A\left(L_{h}+M\right)^{\gamma-2} \\
& M \quad: \quad \psi(1-\gamma) \gamma A\left(L_{h}+M\right)^{\gamma-2}=\varphi p_{f} \phi\left(2 h^{\prime}(M)+M h^{\prime \prime}(M)\right)
\end{aligned}
$$

Next, eliminate $\psi$ and $\varphi$ from the above 3 equations to get

$$
w_{h}=b_{h}+\frac{L_{h}\left((1-\gamma) \gamma A\left(L_{h}+M\right)^{\gamma-2} p_{f} \phi\left(2 h^{\prime}(M)+M h^{\prime \prime}(M)\right)\right)}{(1-\gamma) \gamma A\left(L_{h}+M\right)^{\gamma-2}+p_{f} \phi\left(2 h^{\prime}(M)+M h^{\prime \prime}(M)\right)}
$$

\subsection{Determination of Wage in Foreign}

$$
\underset{w_{f}}{\arg \max }\left(E_{f}-U_{f}\right)^{\beta_{f}}\left(\frac{p_{f}-w_{f}}{\rho+\lambda_{f}}\right)^{1-\beta_{f}}
$$

where $E_{f}$ and $U_{f}$ are defined exactly in the manner in which they were defined for Home, that is simply by replacing the subscript $h$ by $f$ in (10) and (11). The first order condition for the above maximization is given by

$$
\left(1-\beta_{f}\right)\left(E_{f}-U_{f}\right)=\beta_{f}\left(\frac{p_{f}-w_{f}}{\rho+\lambda_{f}}\right)
$$

Note from (10) in the text that $E_{f}-U_{f}=\frac{w_{f}-\rho U_{f}}{\rho+\lambda_{f}}$. Therefore, (52) can be written as

$$
w_{f}=\left(1-\beta_{f}\right) \rho U_{f}+\beta_{f} p_{f}
$$

Next, from (11) in the text obtain $\rho U_{f}=b_{f}+\mu_{f} \theta_{f}\left(E_{f}-U_{f}\right)$. Substitute this in (52) and use (32) to obtain

$$
\rho U_{f}=b_{f}+\frac{\beta_{f} c_{f} \theta_{f}}{1-\beta_{f}}
$$

Substituting (54) in (53) obtain the expression for wage below.

$$
w_{f}=\left(1-\beta_{f}\right) b_{f}+\beta_{f} c_{f} \theta_{f}+\beta_{f} p_{f}
$$




\subsection{Calibration Parameters for Sweden}

Calculation of job destruction rate and exit rate from unemployment based on Albrecht et al (2006).

Using the data on elapsed unemployment duration (AKU table 49) Albrecht et al fit an exponential distribution and estimate the exit rate out of unemployment for low skilled to be 1.867 and for medium skilled to be 2.163. Total unemployment of these two groups is .077. The fraction $\gamma_{1}$ of the unemployed is low skilled and the fraction $\gamma_{2}$ is medium skilled. $p_{1}$ is the fraction of low skilled in the labor force. $p_{2}$ is the fraction of medium skilled. $\delta_{1}$ is the job destruction rate for low skilled job and $\delta_{2}$ for medium skilled job. $\phi_{1}$ is the fraction of vacancies requiring low skill and $\phi_{2}$ is the fraction requiring medium skill. $e_{11}$ : unskilled employed in unskilled jobs. $e_{21}:$ medium skilled employed in low skilled jobs; $e_{22}$ : medium skilled employed in medium skilled jobs. $m(\theta)$ exit rate for medium skilled. The data are the following.

$$
u=.077 ; p_{1}=.648 ; p_{2}=.352 ; \gamma_{1}=.724 ; \gamma_{2}=.276 ; u_{1}=.086 ; u_{2}=.060
$$

Exponential distribution for unemployment duration

$$
m(\theta) \phi_{1}=1.867 ; m(\theta)\left(\phi_{1}+\phi_{2}\right)=2.163=m(\theta)
$$

The above implies

$$
m(\theta)=2.163 ; \phi_{1}=.863 ; \phi_{2}=.137
$$

Steady state implies the following three conditions for job creation to equal job destruction.

$$
\phi_{1} m(\theta) \gamma_{1} u=\delta_{1} e_{11} ; \phi_{1} m(\theta) \gamma_{2} u=\delta_{1} e_{21} ; \phi_{2} m(\theta) \gamma_{2} u=\delta_{2} e_{22}
$$

Now, $e_{11}=p_{1}-\gamma_{1} u=.592$, therefore, $\delta_{1}=.176$. This implies $e_{21}=.225$. Since $e_{11}+e_{21}+e_{22}=$ $1-u=.923, e_{22}=.106$. This in turn implies $\delta_{2}=.059$. That is

$$
\delta_{1}=.176 ; \delta_{2}=.059 ; e_{11}=.592 ; e_{21}=.225 ; e_{22}=.106
$$

We are interested in calculating the average job destruction rate $\delta$ and the exit rate $\bar{m}(\theta)$. Summing up the three s-s conditions obtain

$$
\begin{aligned}
\left(\phi_{1} \gamma_{1}+\phi_{1} \gamma_{2}+\phi_{2} \gamma_{2}\right) m(\theta) u & =\delta_{1} e_{11}+\delta_{1} e_{21}+\delta_{2} e_{22} \\
\left(\phi_{1}+\phi_{2} \gamma_{2}\right) m(\theta) u & =\delta_{1} e_{11}+\delta_{1} e_{21}+\delta_{2} e_{22}
\end{aligned}
$$


Therefore, $\bar{m}(\theta)=\left(\phi_{1}+\phi_{2} \gamma_{2}\right) m(\theta)$ is the exit rate from unemployment for the two skill types as a whole, and $\delta=\frac{\delta_{1} e_{11}+\delta_{1} e_{21}+\delta_{2} e_{22}}{1-u=e_{11}+e_{21}+e_{22}}$ is the job destruction rate for the groups combined.

$$
\bar{m}(\theta)=\left(\phi_{1}+\phi_{2} \gamma_{2}\right) m(\theta)=(.863+.137 * .276) 2.163=1.948 ; \delta=.1625
$$

These are the two key numbers that we are going to use in our calibration. In our notation $\delta$ corresponds to $\lambda_{h}$ and $\bar{m}(\theta)$ corresponds to $\mu_{h} \theta_{h}^{\delta_{h}}$.

\section{Table 1: Calibration Parameter Values for Sweden}

\begin{tabular}{|c|c|c|c|}
\hline Parameter & Description & Value & Source \\
\hline$\rho$ & Annual rate of discount & .05 & Albrecht et al.(2006) \\
\hline$\delta_{h}$ & Elasticity of matching function & .5 & Albrecht et al.(2006) \\
\hline$\lambda_{h}$ & Annual job destruction rate . & .165 & based on Albrecht et al (2006) \\
\hline$b_{h}$ & Unemployment benefit (replacement rate) & $.67 w_{h}$ & $\operatorname{OECD}(1999)^{a}$ \\
\hline$\gamma$ & Production Function parameter & .66 & OECD $(1999)^{b}$ \\
\hline$\mu_{h} \theta_{h}^{\delta_{h}}$ & Exit Rate from Unemployment & 1.948 & based on Albrecht et al (2006) \\
\hline$\theta_{h}$ & Market tightness & 0.5 & Hall (2005) \\
\hline$\mu_{h}$ & Scale parameter in the matching function & 2.755 & Obtained from $\mu_{h} \theta_{h}^{\delta_{h}}$ and $\theta_{h}$ \\
\hline$\phi$ & Offshoring cost & 1.5 & Arbitrary \\
\hline$A$ & Aggregate productivity parameter & 1 & Normalization \\
\hline $\bar{L}_{h}$ & Size of Labor Force & 1 & Normalization \\
\hline$c_{h}$ & Recruitment cost & free & to match $u_{h}=.077$ and $\frac{M}{L_{h}+M}=.07$ \\
\hline$p_{f}$ & Price of offshored input & free & to match $u_{h}=.077$ and $\frac{M}{L_{h}+M}=.07$ \\
\hline$\beta_{h}$ & Bargaining power of workers & 0.5 & Felbermayr et al. (2011) \\
\hline
\end{tabular}

\subsubsection{Parameters for Foreign in the two country case}

Parameter values for Foreign in the two country case: $\bar{L}_{f}=1, \beta_{f}=.5, b_{f}=.2 ; \delta_{f}=\delta_{h}=.5 ; \rho=$ $.05 ; \lambda_{f}=\lambda_{h}=.165, \theta_{f}=.18 . \mu_{f}$ and $c_{f}$ are the free parameters that are chosen to be consistent with 
the baseline values of $p_{f}$ and $F$ obtained for Sweden with $\phi=1.5$ and $h(M)=1+M$. That is, we use the baseline value of parameters underlying figure 1 for Sweden and choose $\mu_{f}$ and $c_{f}$ for Foreign consistent with the implied values of $p_{f}$ and $F$, the two variables that are relevant for Foreign. One downside of this approach is that since $F=.07$ in the baseline case for Sweden, Foreign employment in the input production is very small given the normalization $\bar{L}_{f}=1$. The rest produce the final good using home production technology and show up as unemployed in our figures. Therefore, the absolute value of the unemployment rate for Foreign is not going to be realistic. Only the direction of change in the unemployment for Foreign is informative. 
Figure 1: Unemployment, Wage, and Offshoring (Linear adaptation cost)
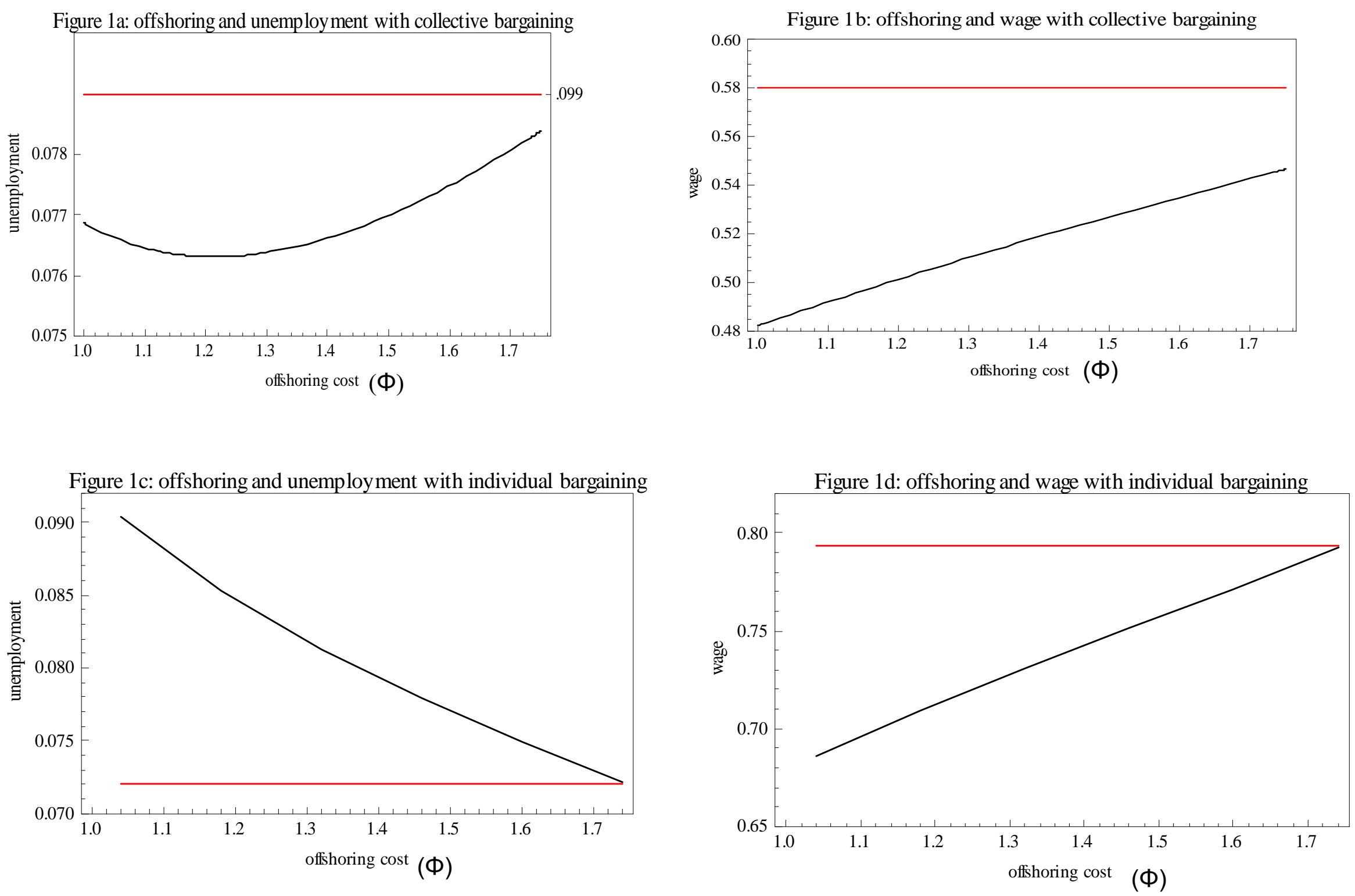


\section{Figure 2: Unemployment, Wage, and Offshoring (Convex adaptation cost)}
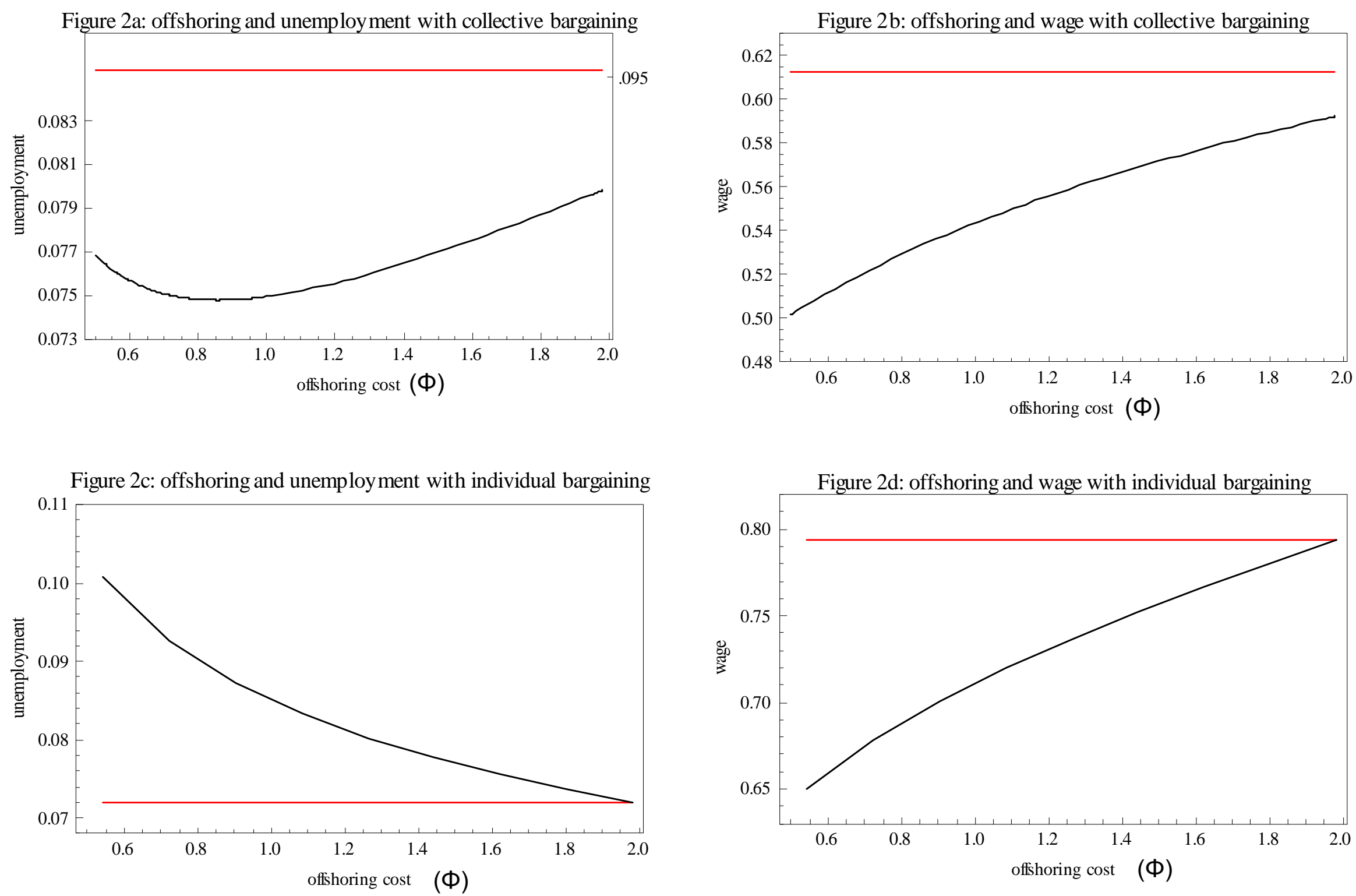


\section{Figure 3: Unemployment, Wage, and Offshoring (Concave adaptation cost)}
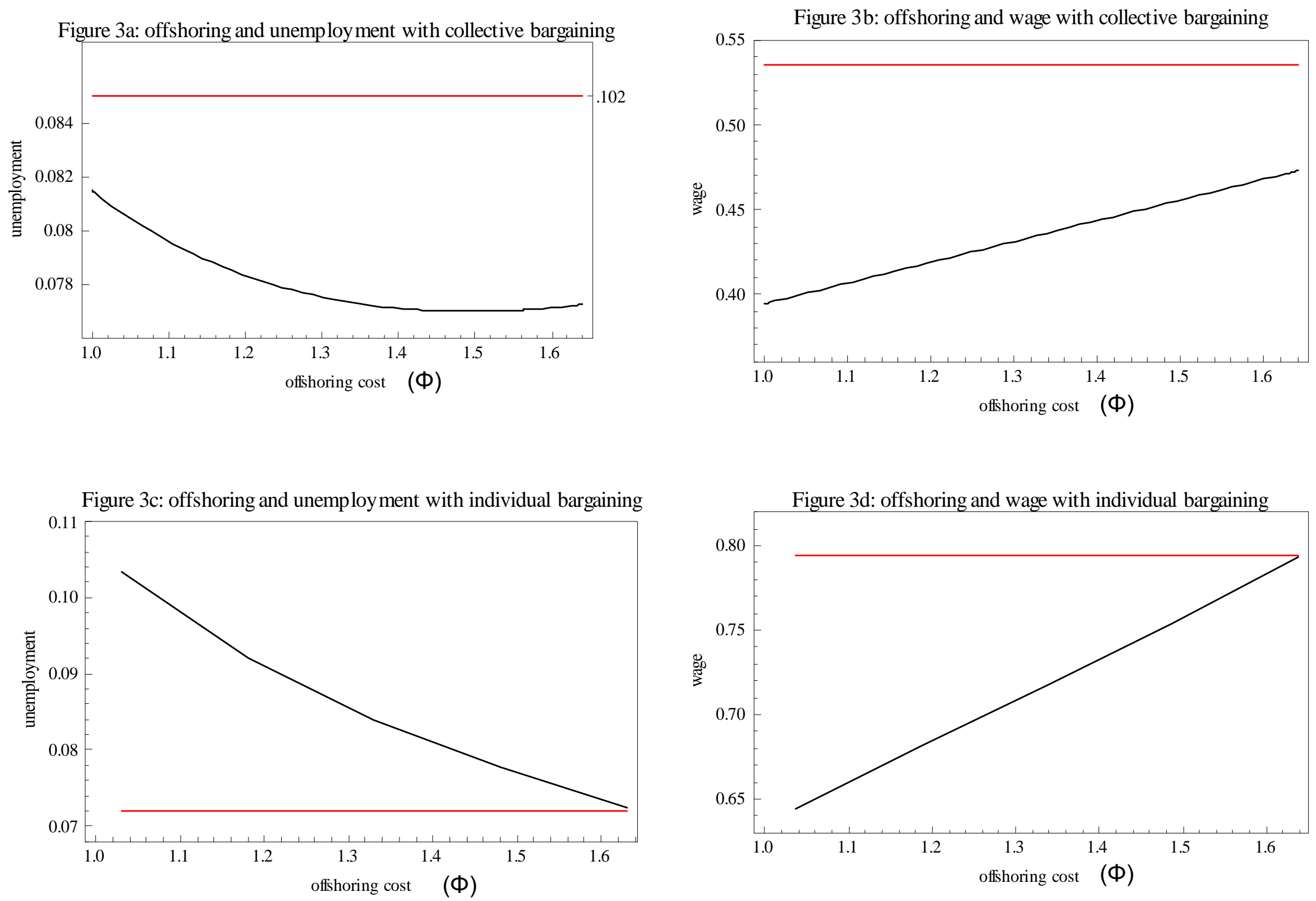
Figure 4: Offshoring and Unemployment with CES Production Function
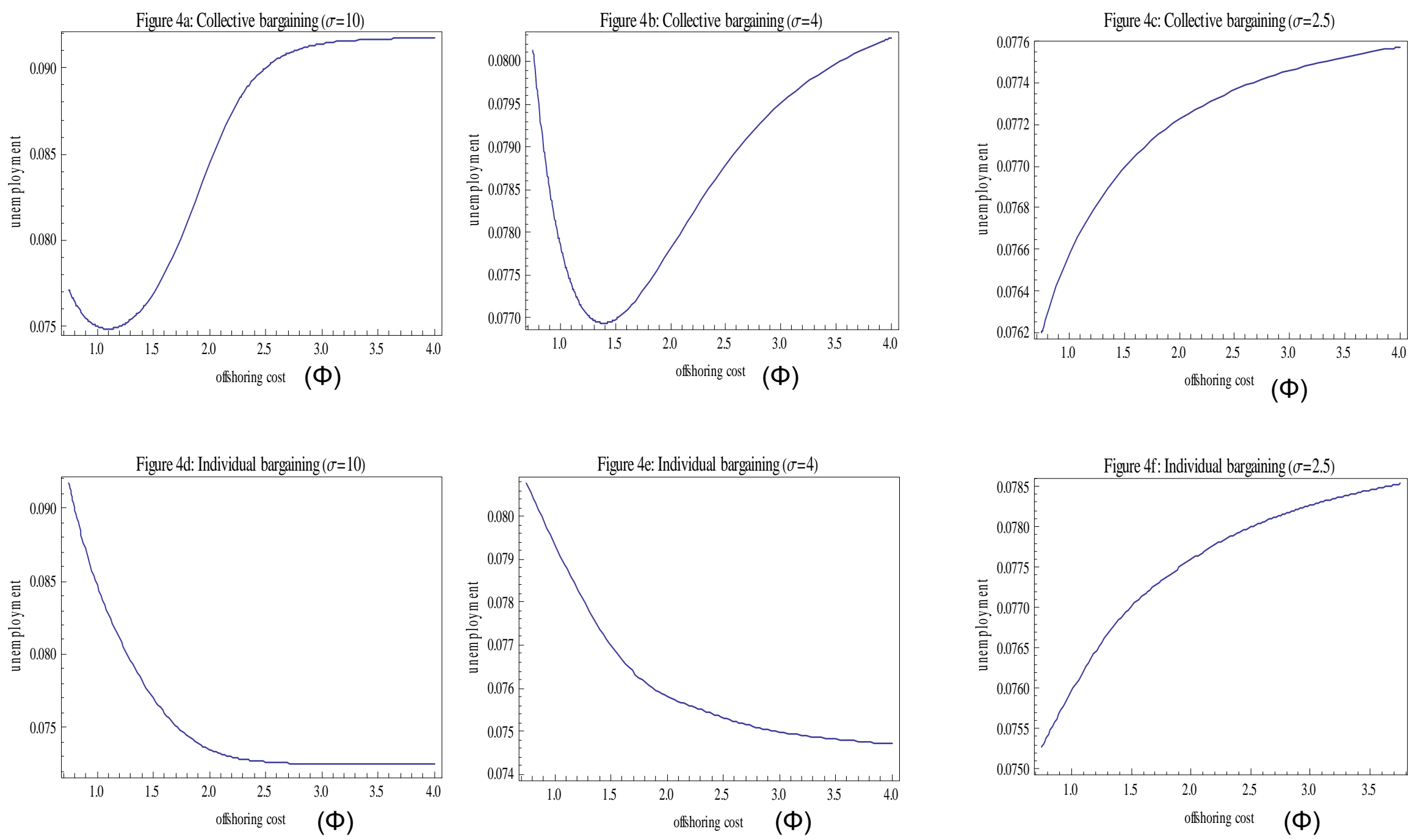
Figure 5a: Labor Market Equilibrium in Foreign

Figure 5b: Determination of World Price
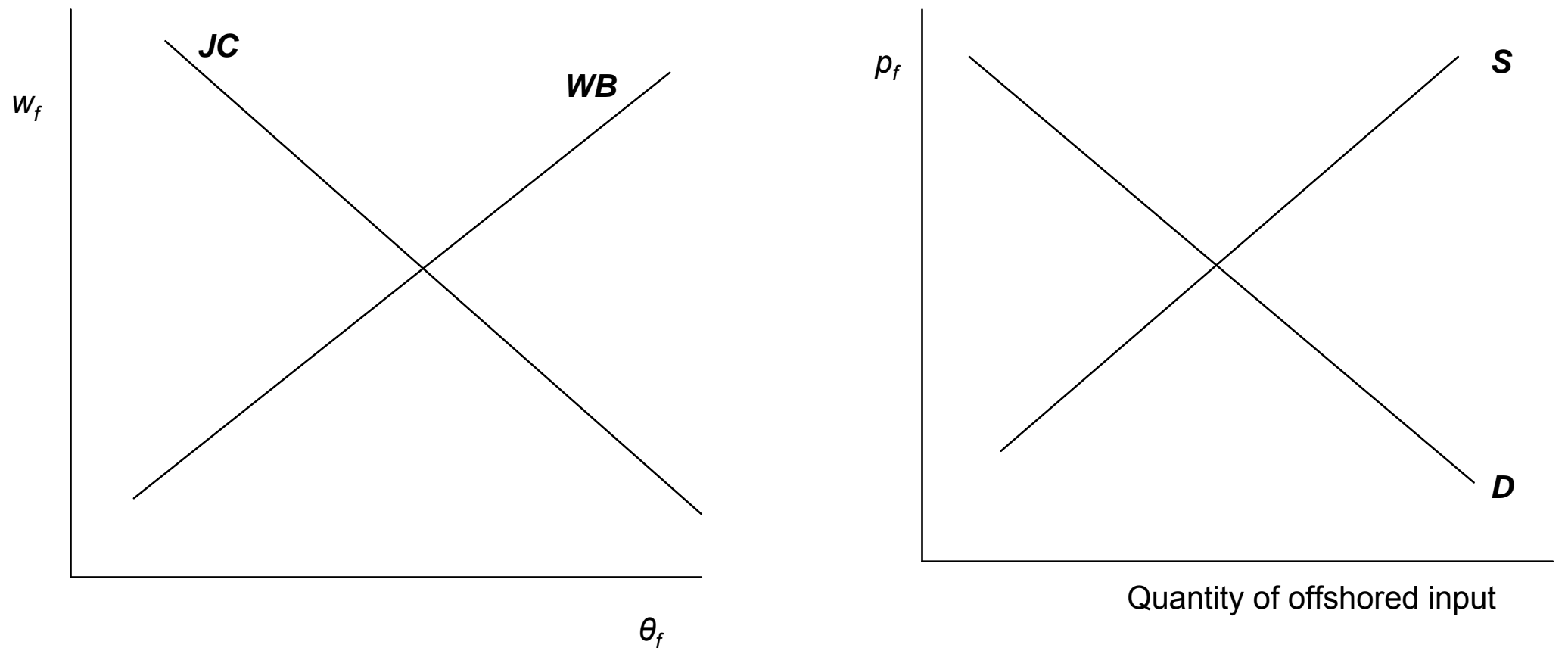
Figure 6: Gross Offshoring as a function of offshoring cost
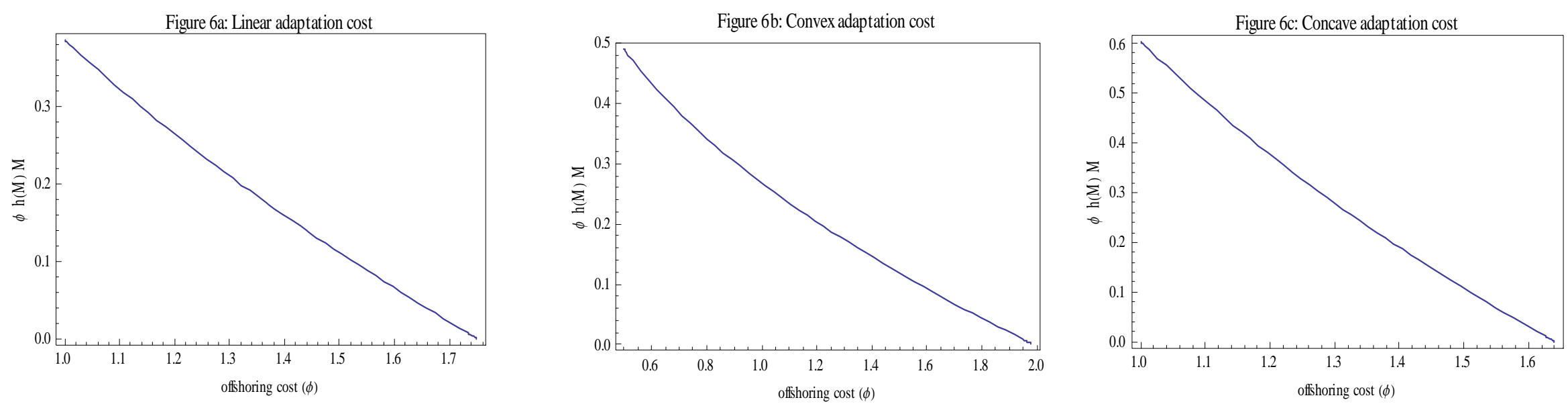

Figure 7: Offshoring and Home unemployment with endogenous $p_{f}$
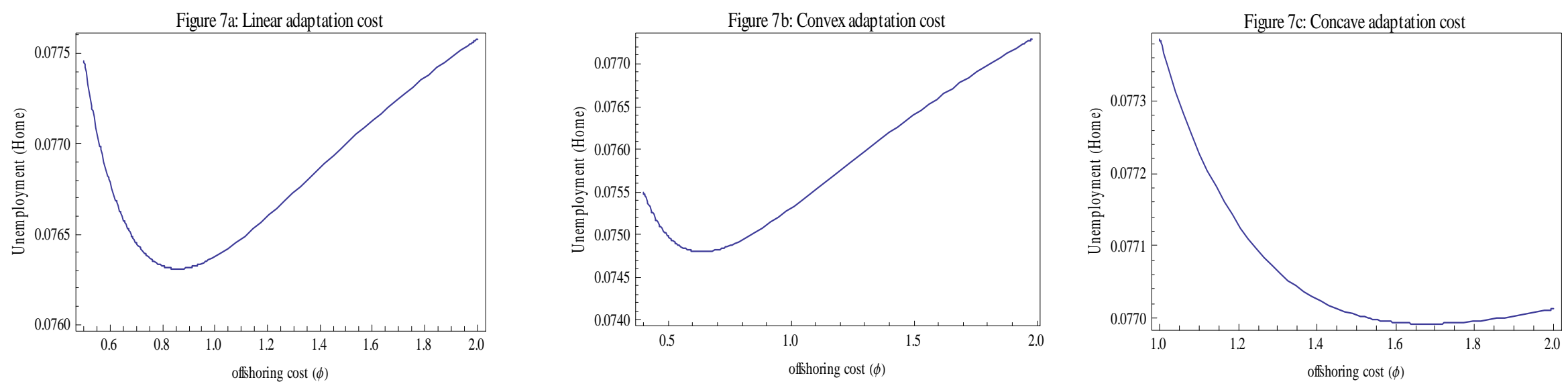